\title{
DESIGN FORMULA TO EVALUATE THE NSM FRP STRIPS SHEAR STRENGTH CONTRIBUTION
}

\section{TO A RC BEAM}

Vincenzo Bianco ${ }^{1}$, Giorgio Monti ${ }^{2}$ and J.A.O. Barros ${ }^{3}$

\begin{abstract}
:
This paper presents the closing step of a synthesis process aiming at deriving, from a previously developed more complex model, a simple design formula to evaluate the shear strength contribution provided by a system of Near Surface Mounted (NSM) Fiber Reinforced Polymer (FRP) strips to a Reinforced Concrete (RC) beam. The self-contained and ready-to-implement set of analytical equations and logical operations is presented along with the main underlying physical-mechanical principles and assumptions. The formulation proposed is appraised against some of the most recent experimental results and its predictions are also compared with those obtained by the two previous and more sophisticated versions of the same modeling strategy. Monte Carlo simulations are carried out in order to appraise the sensitivity of the NSM shear strength contribution prediction to the value assumed by the input parameters.
\end{abstract}

Keywords: Shear; Strengthening; FRP; C. Analytical modeling; Monte Carlo simulations.

\section{Introduction}

Shear strengthening of RC beams by NSM technique consists of gluing FRP strips by a structural adhesive into thin shallow slits cut onto the concrete cover of the beam web lateral faces. A comprehensive three-dimensional mechanical model to predict the NSM FRP strips shear strength contribution to a RC beam was recently proposed (Bianco 2008, Bianco et al. 2009a-b and 2010). That model was developed fulfilling equilibrium, kinematic compatibility and constitutive laws of both the materials involved (FRP and concrete), as well as the local bond between themselves. Despite its consistency with experimental recordings, that model turned out to be somehow cumbersome to be easily implemented and accepted by professional structural engineers. More recently, a simpler version of that model was derived from the more complex one by introducing the following simplifications (Bianco 2008, Bianco et al. 2011): 1) a bi-linear rigid-softening local bond stress-slip diagram was adopted instead

\footnotetext{
${ }^{1}$ Post Doctoral Reseracher, Dept. of Structural Engrg. and Geotechnics, Sapienza University of Rome, via A. Gramsci 53, 00197 Rome, taly. E-mail: vincenzo.bianco@uniroma1.it, corresponding Author. Tel. +39 0649919254, Fax. +39 063221449.

${ }^{2}$ Full Professor, Dept. of Structural Engrg. and Geotechnics, Sapienza University of Rome, via A. Gramsci 53, 00197 Rome, Italy. E-mail: giorgio.monti@uniroma1.it.

${ }^{3}$ Full Professor, Dept. of Civil Engineering, University of Minho, Campus de Azurém, 4810-058 Guimarães, Portugal. E-mail: barros@civil.uminho.pt .
} 
of a multilinear diagram, 2) concrete fracture surface was assumed as semi-pyramidal instead of semi-conical, 3) attention was focused on the average-available-bond-length NSM FRP strip glued on the relevant prism of surrounding concrete, 4) determining the constitutive law of the average-available-bond-length NSM strip, along the approach followed for Externally Bonded Reinforcement (EBR) by Monti et al. (2003), and 5) determining the maximum effective capacity attainable by the average-available-bond-length NSM strip bridging the shear failure crack, imposing a coherent kinematic mechanism (e.g. Monti et al. 2004, Monti and Liotta 2007). Nevertheless, even the second version of that model resulted not easy enough to be accepted by structural engineers since, in order to obtain the constitutive law of the average-available-bond-length NSM strip, it is necessary to implement an iterative procedure simulating the increasing value of the imposed end slip.

In the present paper, the main physical features of a more simplified version of that mechanical model are presented along with the further simplifications introduced with respect to the former version.

During the loading process of a RC beam subject to shear, when concrete average tensile strength $f_{c t m}$ is attained at the web intrados (Fig. 1), some shear cracks originate therein and successively progress towards the web extrados. The governing shear failure crack, herein designated as Critical Diagonal Crack (CDC), is inclined of an angle $\theta$ with respect to the beam longitudinal axis (Fig. 1a). The CDC can be schematized as an inclined plane dividing the web into two portions sewn together by the crossing strips (Fig. 1a). At load step $t_{1}$, the two web parts, separated by the CDC, start moving apart by pivoting around the crack tip whose trace, on the web face, is point $E$ in Fig. 1a. From that step on, by increasing the applied load, the CDC opening angle $\gamma\left(t_{n}\right)$ progressively widens (Fig. 1a). The strips crossing the CDC oppose its widening by anchoring to the surrounding concrete to which they transfer, by bond, the force originating at their intersection with the CDC, $O_{i}^{l}$, as a result of the imposed end slip $\delta_{L i}\left[\gamma\left(t_{n}\right)\right]$, Fig. 1d. The capacity of each strip is provided by its available bond length $L_{f i}$ that is the shorter between the two parts into which the crack divides its actual length $L_{f}$ (Fig. 1a). Bond is the mechanism through which stresses are transferred to the surrounding concrete (Yuan et al. 2004, Mohammed Ali et al. 2006 and 2007, Bianco et al. 2009b). The local bond stress-slip relationship $\tau(\delta)$, comprehensively simulating the mechanical phenomena occurring at 1) the strip-adhesive interface, 2) within the adhesive layer and at 3) the adhesive-concrete interface, can be represented, in a simplified way, by a bi-linear curve (Fig. 1b). The subsequent phases undergone by bond during the loading process, representing the physical phenomena occurring in sequence within the adhesive layer by increasing the imposed end slip, are: "rigid", "softening friction" and "free slipping" (Fig. 1b) (Bianco 2008). The first rigid branch $\left(0-\tau_{0}\right)$ represents the overall initial shear strength of the joint, independent 
of the deformability of the adhesive layer and attributable to the micro-mechanical and mainly chemical properties of the involved materials and relative interfaces. In fact, the parameter $\tau_{0}$ is the average of the following physical entities encountered in sequence by stresses flowing from the strip to the surrounding concrete, i.e.: adhesion at the strip-adhesive interface, cohesion within the adhesive itself, and adhesion at the adhesive-concrete interface (e.g. Sekulic and Curnier 2006, Zhai et al. 2008).

The $\tau(\delta)$ curve adopted (Fig. 1b) envisages that, by imposing an increasing end slip to the FRP strip, cracks form instantaneously within the adhesive layer, both orthogonally to the (inclined) tension isostatics and along the strip-adhesive and adhesive-concrete interfaces (e.g. Sena-Cruz and Barros 2004). Stresses are transferred by friction and micro-mechanical interlock along those micro-cracks. Nonetheless, by imposing an increasing end slip, those cracks progressively become smoother (softening friction phase) up to the point $\left(\delta_{L i}=\delta_{1}\right)$ in which friction can no longer be mobilized and the strip is pulled out without having to overcome any restraint left (free slipping phase).

The constitutive law $V_{f i}\left(L_{R f i} ; \delta_{L i}\right)$ of an NSM FRP strip, i.e. the force transmissible by a strip with resisting bond length $L_{R f i}$ as function of the imposed end slip $\delta_{L i}$, can be determined by analyzing the behavior of the simple structural element composed of the NSM FRP strip within a concrete prism (Fig. 1a,c-d) whose transversal dimensions are limited by the spacing $s_{f}$ between adjacent strips and half of the web cross section width $b_{w} / 2$. In this way, the problem of interaction between adjacent strips (Dias and Barros 2008, Rizzo and De Lorenzis 2009) is taken into account in a simplified way, i.e., by limiting the concrete volume into which subsequent fractures can form, to the amount of surrounding concrete pertaining to the single strip in dependence of $s_{f}$ and $b_{w}$. Moreover, even though the interaction with existing stirrups is herein neglected, it may be also accounted for by limiting the transversal dimension of the concrete prism to a certain ratio of $b_{w} / 2$, since the larger the amount of stirrups, the shallower concrete fracture is expected to be, even if further research is necessary in this respect. Attention can be focused on the system composed of the strip with the average value of available bond length glued on the pertaining prism of surrounding concrete (Fig. 1c-d). The failure modes of an NSM FRP strip subject to an imposed end slip comprise, depending on the relative mechanical and geometrical properties of the materials involved: debonding, tensile rupture of the strip, concrete semi-pyramidal tensile fracture, and a mixed shallowsemi-pyramid-plus-debonding failure mode (Fig. 1e). The term debonding is adopted to designate loss of bond due to damage initiation and propagation within the adhesive layer and at the FRP strip-adhesive and adhesive-concrete interfaces, so that the strip pulling out results (Fig. 1e). When principal tensile stresses transferred to the 
surrounding concrete attain its tensile strength, concrete fractures along a surface, envelope of the compression isostatics, whose shape can be conveniently assumed as a semi-pyramid with principal generatrices inclined of an angle $\alpha$ with respect to the strip longitudinal axis (Fig. 1c-d). Increasing the imposed end slip can result in subsequent semi-pyramidal and coaxial fracture surfaces in the concrete surrounding the NSM strip. This concrete fracture process progressively reduces the resisting bond length $L_{R f i}$ that is the portion of the initial available bond length $L_{f i}$ still bonded to concrete. Those subsequent fractures can either progress up to the free end, resulting in a concrete semi-pyramidal failure, or stop progressing midway between loaded and free end, resulting in a mixed-shallow-semi-pyramid-plus-debonding failure (Fig. 1e). Moreover, regardless of an initial concrete fracture, the strip can rupture (Fig. 1e).

This modeling strategy can be further simplified introducing the following assumptions: 1) concrete fracture can be accounted for determining the equivalent value of the average resisting bond length $\bar{L}_{R f i}^{e q}$, which is the portion of the available average resisting bond length $\bar{L}_{R f i}^{e q}=\eta \cdot \bar{L}_{R f i}(0 \leq \eta \leq 1)$ that would still be adhered to surrounding concrete, as function of the concrete mechanical properties, after all the successive co-axial semi-pyramidal fracture surfaces have formed in the surrounding concrete, and 2) the post peak behavior of the bond-based constitutive law $V_{f i}^{b d}\left(\bar{L}_{R f i}^{e q} ; \delta_{L i}\right)$ of the equivalent value of the average resisting bond length can be neglected. As to the first assumption, the value of concrete average tensile strength $f_{c t m}^{*}$ for values larger than which concrete does not fracture at all $(\eta=1)$ can be determined by imposing the equality between the maximum value of force that $\bar{L}_{R f i}$ can transfer through bond stresses, and the corresponding value of concrete semi-pyramidal fracture strength. In other words, instead of imposing an increasing value of imposed end slip $\delta_{L i}$ to $\bar{L}_{R f i}$ and analyzing how it progressively reduces at the occurrence of successive co-axial concrete fractures (Bianco et al. 2011), one can assume that, if concrete does not fracture for the value of $\delta_{L i}$ in correspondence of which the force transferred through bond by $\bar{L}_{R f i}$ has attained its maximum value, even more it will not fracture either for smaller values of $\delta_{L i}$, or for larger values of $\delta_{L i}$. This is due to the fact that the maximum value of force that $\bar{L}_{R f i}$ can transfer through bond is attained for the value of $\delta_{L i}$ in correspondence of which the distribution of bond stresses has reached the strip free extremity, if $\bar{L}_{R f i} \leq L_{R f e}$, and when the bond transfer length has matched the effective resisting bond length, if $\bar{L}_{R f i}>L_{R f e}$. For a null value of $f_{c t m}$, the assumption is made that concrete semi-pyramidal 
successive co-axial fracture surfaces would reach the average available bond length free extremity resulting in $\bar{L}_{R f i}^{e q}=0(\eta=0)$. It is also assumed that, for values of concrete tensile strength $0<f_{c t m}<f_{c t m}^{*}$, the reduction factor $\eta$ has a linear trend between zero and unit $0 \leq \eta \leq 1$ (Fig. 2).

The maximum value of the effective capacity $V_{f i, e f f}^{\max }$, which is the maximum value of the average of the NSM FRP strip capacity along the CDC (Bianco et al. 2011), can be approximated, and lightly underestimated, neglecting the post peak behavior of the bond-based constitutive law of the equivalent resisting bond length.

In the following paragraphs the resulting analytical equations are firstly presented and then are applied to simulate some of the most recent experimental results. Moreover, Monte Carlo simulation are carried out in order to assess the sensitivity of the results provided by the proposed formulation to the value assumed by the input parameters.

\section{Proposed design formula}

The input parameters include (Fig. 1): beam cross-section web's depth $h_{w}$ and width $b_{w}$; inclination angle of both $\mathrm{CDC}$ and strips with respect to the beam longitudinal axis, $\theta$ and $\beta$, respectively; strips spacing measured along the beam axis $s_{f}$; angle $\alpha$ between axis and principal generatrices of the semi-pyramidal fracture surface (Fig. 1c-d); concrete average compressive strength $f_{c m}$; FRP tensile strength $f_{f u}$ and Young's modulus $E_{f}$; thickness $a_{f}$ and width $b_{f}$ of the strip cross-section, and values of bond stress $\tau_{0}$ and slip $\delta_{1}$ defining the adopted local bond stress-slip relationship (Fig. 1b).

The implementation of the proposed calculation procedure comprehends the following steps (Fig. 3): 1) evaluation of the average value of the available (resisting) bond length $\bar{L}_{R f i}$ and of the minimum integer number $N_{f \text {,int }}^{l}$ of NSM strips that can effectively cross the CDC; 2) evaluation of various constants, both integration and geometric ones; 3) evaluation of the reduction factor $\eta$ of the average value of the available (resisting) bond length and of the equivalent value of the average resisting bond length $\left.\bar{L}_{R f i}^{e q} ; 4\right)$ evaluation of the value of the imposed end slip $\delta_{L u}$ in correspondence of which the peak value of the force transmissible through bond by the equivalent value of the resisting bond length $\bar{L}_{R f i}^{e q}$ can be attained; 5) evaluation of the maximum effective capacity that a NSM of bond length $\bar{L}_{R f i}^{e q}$ can attain during the beam loading process ( $\left.V_{f i, e f f}^{\max }\right)$, and 6) evaluation of the strips shear strength contribution $V_{f}$. 
Average value of the available resisting bond length $\bar{L}_{R f i}$ and minimum number of strips $N_{f, \text { int }}^{l}$ effectively crossing the $C D C$

The average value of the available bond length and the minimum integer number of strips effectively crossing the CDC can be evaluated as follows (Fig. 1):

$$
\begin{gathered}
\bar{L}_{R f i}=\frac{h_{w} \cdot \sin \theta \cdot(\cot \theta+\cot \beta)}{4 \cdot \sin (\theta+\beta)} \\
N_{f, \text { int }}^{l}=\text { round off }\left[h_{w} \cdot \frac{(\cot \theta+\cot \beta)}{s_{f}}\right]
\end{gathered}
$$

\section{Evaluation of Constants}

It is necessary to calculate some constants, both geometrical and integration ones, characterizing the bond transfer mechanism of the adopted NSM system, composed of a certain type of FRP strips, adhesive and concrete (Bianco et al. 2011). The geometric constants encompass (Fig. 1):

$$
L_{p}=2 \cdot b_{f}+a_{f}
$$

the effective perimeter of the strip cross section;

$$
A_{c}=s_{f} \cdot \frac{b_{w}}{2}
$$

the cross section area of the relevant prism of surrounding concrete; and

$$
L_{d}=\frac{h_{w}}{\sin \theta}
$$

the CDC length.

The mechanical constants encompass:

$$
V_{f}^{t r}=a_{f} \cdot b_{f} \cdot f_{f u}
$$

the strip tensile strength;

$$
f_{c t m}=1.4 \cdot\left(\left(f_{c m}-8\right) / 10\right)^{\frac{2}{3}}
$$

concrete mean tensile strength; and

$$
E_{c}=2.15 \cdot 10000 \cdot\left(f_{c m} / 10\right)^{\frac{1}{3}}
$$

concrete's Young's modulus, where both $E_{c}$ and $f_{c t m}$ are herein evaluated by means of the formulae present in the CEB-FIP Model Code 1990, with $f_{c m}$ in MPa.

The bond-modeling constants encompass (see the Appendix): 


$$
J_{1}=\frac{L_{p}}{A_{f}} \cdot\left[\frac{1}{E_{f}}+\frac{A_{f}}{A_{c} \cdot E_{c}}\right] ; \frac{1}{\lambda^{2}}=\frac{\delta_{1}}{\tau_{0} \cdot J_{1}} ; C_{3}=\frac{V_{f}^{t r} \cdot J_{1}}{L_{p} \cdot \lambda}
$$

that are integration constants regarding the bond transfer mechanism;

$$
L_{R f e}=\frac{\pi}{2 \cdot \lambda} ; V_{f 1}^{b d}=\frac{L_{p} \cdot \lambda \cdot \delta_{1}}{J_{1}}
$$

the effective resisting bond length $L_{R f e}$, and the corresponding maximum bond force $V_{f 1}^{b d}$.

\section{Reduction factor $\eta$ and equivalent value of the average resisting bond length $\bar{L}_{R f i}^{e q}$}

The reduction factor can be evaluated as follows:

$$
\eta\left(s_{f} ; b_{w} ; f_{c m} ; \bar{L}_{R f i}\right)= \begin{cases}f_{c t m} / f_{c t m}^{*} & \text { se } f_{c t m}<f_{c t m}^{*} \\ 1 & \text { se } f_{c t m} \geq f_{c t m}^{*}\end{cases}
$$

where:

$$
f_{c t m}^{*}=\frac{L_{p} \cdot \lambda \cdot \delta_{1} \cdot \sin \left(\lambda \cdot L_{R f i}\right)}{J_{1} \cdot \min \left(L_{R f i} \cdot \tan \alpha ; \frac{b_{w}}{2}\right) \cdot \min \left(s_{f} \cdot \sin \beta ; 2 \cdot L_{R f i} \cdot \tan \alpha\right)}
$$

in which $L_{R f i}$ has to be set equal to:

$$
L_{R f i}=\left\{\begin{array}{lll}
\bar{L}_{R f i} & \text { if } & \bar{L}_{R f i} \leq L_{R f e} \\
L_{R f e} & \text { if } & \bar{L}_{R f i}>L_{R f e}
\end{array}\right.
$$

The value of $f_{c t m}^{*}$ is the one corresponding, under the above simplifying assumptions, for a given average NSM system, to the limit condition of occurrence of concrete fracture.

The equivalent value of the average resisting bond length is given by:

$$
\bar{L}_{R f i}^{e q}=\bar{L}_{R f i} \cdot \eta\left(s_{f} ; b_{w} ; f_{c m} ; \bar{L}_{R f i}\right)
$$

Value of the imposed end slip $\delta_{L u}$ in correspondence of which the peak value of the comprehensive constitutive law $V_{f i}\left(\bar{L}_{R f i}^{e q} ; \delta_{L i}\right)$ of the equivalent average resisting bond length $\bar{L}_{R f i}^{e q}$ is attained

In case the maximum invariant value of force that a given NSM system, characterized by a given FRP strip, a given adhesive layer and concrete, can transfer through bond stresses $V_{f 1}^{d b}$ is larger or equal to the strip tensile strength $V_{f}^{t r}$, the value of imposed end slip in correspondence of which the peak value of the constitutive law $V_{f i}\left(\bar{L}_{R f i}^{e q} ; \delta_{L i}\right)$ is assumed as the minimum between $\delta_{L 1}\left(\bar{L}_{R f i}^{e q}\right)$ and $\delta_{L 1}\left(V_{f}^{t r}\right)$ (Fig. 2d), where $\delta_{L 1}\left(\bar{L}_{R f i}^{e q}\right)$ is the value of imposed 
end slip in correspondence of which the bond-based constitutive law $V_{f i}^{b d}\left(\bar{L}_{R f i}^{e q} ; \delta_{L i}\right)$ attains the peak value, and $\delta_{L 1}\left(V_{f}^{t r}\right)$ is the value of the imposed end slip in which the bond transferred force equals the strip tensile strength $\left(V_{f}^{t r}=a_{f} \cdot b_{f} \cdot f_{f u}\right)$

The value of the imposed end slip $\delta_{L u}$ in correspondence of which the peak force transmissible by the equivalent average resisting bond length $\bar{L}_{R f i}^{e q}$ is attained, is given by:

$$
\delta_{L u}= \begin{cases}\delta_{L 1}\left(\bar{L}_{R f i}^{e q}\right) & \text { se } \quad V_{f 1}^{b d}<V_{f}^{t r} \\ \min \left[\delta_{L 1}\left(\bar{L}_{R f i}^{e q}\right) ; \delta_{L i}\left(V_{f}^{t r}\right)\right] & \text { se } \quad V_{f 1}^{b d} \geq V_{f}^{t r}\end{cases}
$$

where:

$$
\delta_{L 1}\left(\bar{L}_{R f i}^{e q}\right)= \begin{cases}\delta_{1} \cdot\left[1-\cos \left(\lambda \cdot \bar{L}_{R f i}^{e q}\right)\right] & \text { for } \bar{L}_{R f i}^{e q} \leq L_{R f e} \\ \delta_{1} & \text { for } \bar{L}_{R f i}^{e q}>L_{R f e}\end{cases}
$$

and:

$$
\delta_{L i}\left(V_{f}^{t r}\right)=\delta_{1} \cdot\left\{1-\cos \left[-\arcsin \frac{C_{3}}{\delta_{1}}\right]\right\}
$$

Maximum effective capacity $V_{f i, e f f}^{\max }$ of the NSM strip with equivalent average resisting bond length $\bar{L}_{R f i}^{\text {eq }}$

The maximum effective capacity can be evaluated, neglecting the post peak behavior of the constitutive law, as follows (Bianco et al. 2011):

$$
V_{f i, e f f}^{\max }=V_{f i, e f f}\left(\gamma_{\max }\right)=\frac{\delta_{1} \cdot A_{2}}{2 \cdot L_{d} \cdot A_{3} \cdot \gamma_{\max }} \cdot\left[\frac{\pi}{2}-\arcsin \psi-\psi \cdot \sqrt{1-\psi^{2}}\right]
$$

where:

$$
A_{2}=\frac{L_{p} \cdot \lambda}{J_{1}} ; A_{3}=\frac{\sin (\theta+\beta)}{2 \cdot \delta_{1}} ; \gamma_{\max }=\frac{2 \cdot \delta_{L u}}{L_{d} \cdot \sin (\theta+\beta)} ; \psi=1-A_{3} \cdot \gamma_{\max } \cdot L_{d}
$$

\section{Shear strength contribution provided by a system of NSM FRP strips}

The actual $V_{f}$ and design value $V_{f d}$ of the NSM shear strength contribution, can be obtained as follows:

$$
V_{f d}=\frac{1}{\gamma_{R d}} \cdot V_{f}=\frac{1}{\gamma_{R d}} \cdot\left(2 \cdot N_{f, \text { int }}^{l} \cdot V_{f i, e f f}^{\max } \cdot \sin \beta\right)
$$


where $\gamma_{R d}$ is the partial safety factor, divisor of a capacity, that can be assumed as 1.1-1.2 according to the level of uncertainty affecting the input parameters but, in this respect, a reliability-based calibration is needed.

\section{Formulation Appraisal}

The proposed formulation was applied to the RC beams tested by Dias and Barros (2008), Dias et al. (2007), Dias (2008), Rizzo and De Lorenzis (2009), A.K.M. Anwarul Islam (2009), Rahal, K.N. (2010), Rahal and Rumaih (2011), Jalali et al. (2012) and Cisneros et al. (2012).

The beams tested in the first two experimental programs (series I and II) were T cross-section RC beams characterized by the same test set-up with the same ratio between the shear span and the beam effective depth ( $a / d=2.5$ ), the same amount of longitudinal reinforcement, the same kind of CFRP strips and epoxy adhesive and they differed for the concrete mechanical properties. In fact, the first experimental program (series I) was characterized by a concrete average compressive strength $f_{c m}$ of $31.1 \mathrm{MPa}$, while the second (series II) $f_{c m}=18.6$ $M P a$. Both series presented different configurations of NSM strips, in terms of both inclination $\beta$ and spacing $s_{f}$

. The second program also included beams characterized by a different amount of existing steel stirrups (see Table 1). The beams tested in the third experimental program (series III) were characterized by the same test set up, but with a different shear aspect ratio $(a / d=3.3)$ and a higher concrete average compressive strength ( $f_{c m}=59.4 \mathrm{MPa}$ ). Some of them were also subjected to pre-cracking (their label includes a letter F).

Those beams are characterized by the following common geometrical and mechanical parameters: $b_{w}=180 \mathrm{~mm}$; $h_{w}=300 \mathrm{~mm} ; f_{f u}=2952 \mathrm{MPa}$ (for the series I and II) and $f_{f u}=2848 \mathrm{MPa}$ (for the series III); $E_{f}=166.6 \mathrm{GPa}$ (for the series I and II) and $E_{f}=174.3 \mathrm{GPa}$ (for the series III); $a_{f}=1.4 \mathrm{~mm} ; b_{f}=10.0 \mathrm{~mm}$. The CDC inclination angle $\theta$ adopted in the simulations by the proposed formulation, listed in Table 1, is the one experimentally observed by inspecting the crack patterns (Dias 2008). Note that the experimental observations confirm the expected trend according to which $\theta$ diminishes for increasing values of the ratio $a / d$ (e.g. Bousselham and Chaalal 2004, Chao et. al. 2005). In fact, for some beams of the III series $(a / d=3.3), \theta^{\exp }$ assumes values smaller than $45^{\circ}$ and up to $20^{\circ}$ (Table 1). In this respect, it has to be stressed that assuming $\theta=45^{\circ}$ could result excessively conservative since, with respect to smaller values $\left(e . g . \theta=20^{\circ}\right)$, and other parameters being the same, the predicted NSM shear strength contribution decreases due to the fact that the number of strips effectively crossing the CDC diminishes (Bianco 2008). It would be necessary to develop rigorous equations to 
evaluate the CDC inclination angle $\theta$ as function of 1) shear aspect ratio $a / d$ and amount of both 2) NSM strips and 3) existing steel stirrups but, in this respect, further research is necessary.

The beams tested by Rizzo and De Lorenzis (2009) (series IV) were rectangular cross-section RC beams strengthened in shear by either bars (their label starts by NB) or strips (their label starts by NS) and tested under four point bending (Table 2). These beams were characterized by cross-section dimensions of $b_{w}=200 \mathrm{~mm}$ and $h_{w}=210 \mathrm{~mm}$, and the ratio between the shear span and the beam effective depth was $a / d=3.0$. Concrete had average compressive strength of 29.3 MPa. The round CFRP bars have a $8 \mathrm{~mm}$ diameter cross-section and for improvement of the bond properties, the surface of this type of bar is spirally wound with a carbon fiber tow and sand coated. The tensile strength and modulus of elasticity of the bars were $f_{f u}=2.21 \mathrm{GPa}$ and $E_{f}=145.7 \mathrm{GPa}$ , respectively. The strips, have a cross-section of dimensions $a_{f}=2.0 \mathrm{~mm}$ and $b_{f}=16.0 \mathrm{~mm}$, and mechanical properties of $f_{f u}=2.07 \mathrm{GPa}$ and $E_{f}=121.5 \mathrm{GPa}$. Two kinds of epoxy were employed to glue the NSM reinforcement, both two-component $100 \%$ solid non-sag tixotropic epoxy adhesive pastes obtained by mixing resin and hardener in a 3:1 weight ratio, differ by the values of tensile strength and modulus of elasticity and are indicated, in the beam codes, by a letter a or $\mathrm{b}$. The tensile strength and the secant tensile elastic modulus presented values of $18.6 \mathrm{MPa}$ and $4.15 \mathrm{GPa}$, respectively, for the type-a adhesive, and values of $22.8 \mathrm{MPa}$ and $12.87 \mathrm{GPa}$ for the type-b. Since the experimentally observed value of the CDC inclination angle is not reported, in the simulation a value of $45^{\circ}$ was assumed.

The beams tested by A.K.M. Anwarul Islam (2009) (series V) were rectangular cross-section RC beams strengthened in shear by CFRP round bars and tested under four point bending (Table 3). These beams were characterized by cross-section dimensions of $b_{w}=254 \mathrm{~mm}$ and $h_{w}=305 \mathrm{~mm}$, and the ratio between the shear span and the beam effective depth was $a / d=2.34$. Concrete had average compressive strength of $49.75 \mathrm{MPa}$. The round CFRP bars have a $9 \mathrm{~mm}$ diameter cross-section and tensile strength and modulus of elasticity of the bars were $f_{f u}=2.07 \mathrm{GPa}$ and $E_{f}=124.0 \mathrm{GPa}$, respectively. CFRP bars are inclined of $90^{\circ}$ with respect to the beam longitudinal axis and since the experimentally observed value of the CDC inclination angle is not reported, in the simulation a value of $45^{\circ}$ was assumed.

The beams tested by Rahal (2010) and by Rahal and Rumaih (2011) (series VI) were T cross-section RC beams strengthened in shear by NSM bars either of steel (their label includes a letter R) or CFRP (their label includes a letter F) and tested under four point bending (Table 4). All the five tested beams contained two test regions each, one strengthened with CFRP bars and the other with conventional steel bars. Hence, a total of ten results are 
reported. These beams were characterized by T cross-section dimensions of $b_{w}=150 \mathrm{~mm}$ and $h_{w}=400 \mathrm{~mm}$, while the flange was $380 \mathrm{~mm}$ in width and $100 \mathrm{~mm}$ in depth, and the ratio between the shear span and the beam effective depth was $a / d=3.0$. Concrete average compressive strength ranged from $36.2 M P a$ to $38.6 M P a$. The epoxy resin used to grout the bars in the groves was "non-sag" resin. The NSM steel bars were characterized by yield tensile strength of $0.51 \mathrm{GPa}$, while the NSM FRP bars were $8 \mathrm{~mm}$ deformed TYFO ${ }^{\circledR}$ carbon FRP bars characterized by $f_{f u}=1.90 \mathrm{GPa}$ and $E_{f}=124.0 \mathrm{GPa}$. Since the experimentally observed value of the CDC inclination angle is not reported, in the simulation a value of $45^{\circ}$ was assumed.

The beams tested by Jalali et al. (2012) (series VII) were rectangular cross-section RC beams strengthened in shear by Manually Made NSM FRP rods (MMFRPs) with (their label includes a letter A) and without an extremity anchorage (Table 5) and tested under three point bending. These particular kind of FRP rods were obtained by wrapping a dry carbon fiber sheet, which was pre impregnated with resin, around a $6 \mathrm{~mm}$ diameter wooden rod. These rods were characterized by $f_{f u}=3.55 \mathrm{GPa}$ and $E_{f}=235.0 \mathrm{GPa}$. The beams were rectangular crosssection with dimensions $b_{w}=200 \mathrm{~mm}$ and $h_{w}=250 \mathrm{~mm}$, and the ratio between the shear span and the beam effective depth was $a / d=2.73$. Concrete average compressive strength was equal to $f_{c m}=36.4 M P a$. Since the experimentally observed value of the CDC inclination angle is not reported, in the simulation a value of $45^{\circ}$ was assumed.

The beams tested by Cisneros et al. (2012) (series VII) were rectangular cross-section RC beams strengthened in shear by either bars (their label starts by B) or strips (their label starts by S) and tested under three point bending (Table 6). Beams cross-section dimensions were $b_{w}=200 \mathrm{~mm}$ and $h_{w}=350 \mathrm{~mm}$. Each beam was tested twice, once at each end, and the ratio between the shear span and the beam effective depth equal to $a / d=2.9$. Concrete average compressive strength ranged from $f_{c m}=22.84 \mathrm{MPa}$ to $f_{c m}=29.11 \mathrm{MPa}$. The NSM FRP bars were characterized by $8 \mathrm{~mm}$ diameter, while the strips had cross section dimensions of $a_{f}=2.5 \mathrm{~mm}$ and $b_{f}=15.0 \mathrm{~mm}$ . FRP mechanical properties were $f_{f u}=2.5 \mathrm{GPa}$ and $E_{f}=165.0 \mathrm{GPa}$. The resin used was MBrace Adhesive 220 for the bars and Masterflow 920 SF for the strips. Since the experimentally observed value of the CDC inclination angle is not reported, in the simulation a value of $45^{\circ}$ was assumed.

The angle $\alpha$ was assumed equal to $28.5^{\circ}$ for all the experimental programs, being the average of values obtained in a previous investigation (Bianco 2008) by back-analysis of experimental data. As to the value of $\alpha$, due to its importance to the prediction accuracy of NSM shear strength contributions, further research is desirable. Concrete 
average tensile strength $f_{c t m}$ was calculated from the average compressive strength by means of the formulae of the CEB Fib Model Code 1990. The parameters characterizing the adopted local bond stress-slip relationship (Fig. 1b) are for all the experimental programs: $\tau_{0}=20.1 \mathrm{MPa}$ and $\delta_{1}=7.12 \mathrm{~mm}$. Those values were obtained by the values characterizing the more sophisticated local bond stress-slip relationship adopted in previous works (Bianco et al. 2009a, 2010), by fixing the value of $\tau_{0}=20.1 \mathrm{MPa}$ and determining $\delta_{1}=7.12 \mathrm{~mm}$ by equating the fracture energy. In this respect, it has to be underlined that the necessity is felt to develop rigorous equations that would allow the values $\left(\tau_{0}, \delta_{1}\right)$ characterizing the local bond stress slip relationship to be determined on the basis of: a) superficial chemical and micro-mechanical properties of FRP, adhesive and concrete, and b) the adhesive layer thickness. Nonetheless, further research is, in this respect, required. However, as highlighted by means of parametric studies (Bianco 2008), for the values of concrete mechanical properties that can be met in practice, debonding rarely occurs due the high capacity of currently available structural adhesives. Thus, slight variations of the values of the parameters $\tau_{0}$ and $\delta_{1}$ cannot be felt, in terms of NSM shear strength contribution, due to the premature occurrence of other failure modes such as either concrete fracture or strip rupture. For this reason, adopting values of $\tau_{0}=20.1 \mathrm{MPa}$ and $\delta_{1}=7.12 \mathrm{~mm}$ for cases characterized by different values of both 1) superficial chemical-mechanical properties of FRP, adhesive and concrete, and 2) adhesive thickness, is not expected to significantly affect the predictive performance of the proposed formulation.

When NSM round bars are employed instead of strips, the equivalent square cross-section is employed in the calculations. In the case of the MMFRPs adopted by Jalali et al. (2012), since the FRP cross-section is an annulus, the corresponding area is adopted to evaluate $A_{f}$ (with $A_{f}=50.27 \mathrm{~mm}^{2}$ obtaining $a_{f}=b_{f}=7.10 \mathrm{~mm}$ ). The same values of the equivalent square cross section dimensions are adopted to evaluate the effective perimeter $L_{p}=2 \cdot b_{f}+a_{f}$, even though slightly underestimating this latter.

Note also that, for the works among those adopted as basis of the model appraisal, not reporting directly the NSM shear strength contribution $V_{f}^{\mathrm{exp}}$, this latter has been herein obtained as the difference between the shear strength of the strengthened beam and that of the control beam. Note also that in Tables 1-6, the symbol $h_{w}$ has been adopted to indicate also the vertical height of the NSM bars, when they are coincident while, when the NSM bar is inserted through the flange thickness, the symbol $h_{f}$ has been adopted instead.

The predictions obtained by the formulation proposed in the present work have also been compared with those obtained by the previous two more sophisticated versions of the same modeling strategy. The predictions obtained 
by the first model (Bianco et al. 2009a), which contemplates three geometrical configurations that the occurred CDC can assume with respect to the system of NSM FRPs, are labeled by $V_{f, 1}^{I}, V_{f, 2}^{I}$ and $V_{f, 3}^{I}$. The predictions obtained by the second and simplified model (Bianco et al. 2011) are labeled by $V_{f}^{I I}$ while those obtained by the third, further simplified model herein presented are labeled by $V_{f}^{I I I}$. The experimental results concerning beams 2S-8LI45-I and 4S-7LV-II have been neglected in the considerations below since they are deemed affected by some disturbance.

The formulation herein proposed provides, in general, satisfactory estimates of the experimental recordings $V_{f}^{\text {exp }}$ since the ratio $V_{f}^{I I I} / V_{f}^{\text {exp }}$ presents altogether mean value and standard deviation equal to 0.69 and 0.29 , respectively. The second version of the adopted modeling strategy also provides satisfactory estimates of the experimental recordings $V_{f}^{\exp }$ since the ratio $V_{f}^{I I} / V_{f}^{\text {exp }}$ presents altogether mean value and standard deviation equal to 0.67 and 0.29 , respectively, even it is not closed form and requires the implementation of an iterative procedure to determine the average resisting bond length strip's constitutive law. The first version of the adopted modeling strategy, much more sophisticated than the two more recent versions, provides much more satisfactory estimates. In fact, considering, for each analyzed beam, the closest prediction out of the three obtained, the ratio $V_{f} / V_{f}^{\exp }$ presents altogether mean value and standard deviation equal to 0.98 and 0.26 , respectively, even if it is very cumbersome to be implemented and needs a stand-alone software to be developed.

\section{Sensitivity analysis}

A sensitivity analysis was carried out to assess the relative importance of each input parameter on the calculated value of the NSM shear strength contribution in order to figure out what are the input parameters that mostly affect the result. For this purpose, the proposed formulation, presented in the previous sections, was implemented in a spreadsheet that was re-calculated iteratively one hundred thousand times, each time with a set of new possible values of the input parameters. At each iteration, the new value of each parameter was sampled, independently from each other, from the relevant probability distribution assigned to it, and a new value of the output was generated in the corresponding cell. As simulation progressed, new possible outcomes were generated from each iteration and a numerical solver kept track of these output values. All of the input parameters $\left(a_{f}, b_{f}, s_{f}, b_{w}\right.$, $\left.h_{w}, f_{c m}, \alpha, f_{f u}, E_{f}, \theta, \tau_{0}, \delta_{1}\right)$ were characterized by a uniform probability distribution, which means a range 
of possible values with the same likelihood of occurrence (Table 7). These intervals cover the possible situations occurring in NSM shear strengthening interventions for RC beams.

In particular: the strip thickness $a_{f}$ was characterized by a range of variation between 1.0 and $5.0 \mathrm{~mm}$; the strip width $b_{f}$, the strips' spacing $s_{f}$, and the concrete average compressive strength $f_{c m}$ were characterized by ranges of variation 5-35 mm, 50-250 $\mathrm{mm}$ and 10-90 MPa, respectively; beam cross-section web's depth $h_{w}$ and width $b_{w}$ were characterized by ranges of variation $300-700 \mathrm{~mm}$ and $150-400 \mathrm{~mm}$. The input parameters $\tau_{0}$ and $\delta_{1}$ were characterized by ranges of variation $10-30 \mathrm{MPa}$ and $2.0-15.0 \mathrm{~mm}$, respectively.

At each iteration, the value of each input parameter was sampled from the relevant probability distribution by the Monte Carlo Sampling Technique (Law and Kelton 2000, Ang and Tang 1975). Monte Carlo simulations is simply a repeated process of generating deterministic solutions to a given problem; each solution corresponds to a set of deterministic values of the underlying random input parameters. In other words, a Monte Carlo simulation recalculates the worksheet in which the deterministic formulation was implemented, over and over, each time assuming a set of input parameters whose values are selected randomly from the probability distribution assigned to each of them.

The outcome of the above simulations, being the result of calculations in which all input parameters are characterized by a uniform probability distribution, is itself characterized by a probability distribution and can be represented both in terms of probability density and cumulated ascending probability (Fig. 4). From those results it arises that, for the range of variations herein assigned to the input parameters (Table 7): 1) the equivalent average resisting bond length strip's maximum effective capacity $V_{f i, e f f}^{\max }\left(\bar{L}_{R f i}^{e q}\right)$ varies between 0.0 and $40.8 \mathrm{kN}$ in $95 \%$ of cases, and 2) the NSM FRP strips shear strength contribution varies between 0.0 and $514.0 \mathrm{kN}$ in $95 \%$ of cases. The sensitivity analysis between the output and the input variables was herein carried out evaluating, by the multivariate stepwise regression method (e.g. Draper and Smith 1966), the regression coefficients of the input variables (Fig. 4). The larger the coefficient, the larger the impact that particular input has on the calculated value. A positive coefficient, with bar extending to the right, indicates that this input has a positive impact, which means that increasing this input will increase the output, while the opposite happens if the coefficient is negative.

The values of the plotted regression coefficients (Fig. 4) indicate the increment of output for a standard deviation of the relevant input. For instance, $h_{w}$ has a mapped coefficient of 86.50 , meaning that an increase of $\mu$ fraction of a standard deviation of input parameter $h_{w}$ yields an increase of $86.50 \cdot \mu$ units ( $k N$, not standard deviations) 
of the output $V_{f}$. The standard deviation of sampled values of $h_{w}$ is $115.35 \mathrm{kN}$ (Table 8) and, therefore, every unit increase of input $h_{w}$ impacts the output positively by $86.50 / 115.35=0.75 \mathrm{kN}$.

From the sensitivity analysis it was found that the input parameters that mostly affect the value of $V_{f i, e f f}^{\max }$ are, in decreasing order of impact, the angle $\alpha$ between axis and generatrices of the concrete fracture surface, the concrete average compressive strength $f_{c m}$, the beam cross section depth $h_{w}$, and the strips spacing $s_{f}$ (Fig. 4). It was also observed that the value of $V_{f}$ is mostly affected by the value of $h_{w}, \alpha, f_{c m}$, and the CDC inclination angle $\theta$ (Fig. 4).

\section{Conclusions}

A design formulation to predict the NSM FRP strips shear strength contribution to a RC beam was derived from a previously developed numerical model, introducing some simplifications, such as: 1) assuming the phenomenon of concrete fracture just as a reducer of the average available resisting bond length, and evaluating a resulting equivalent average resisting bond length, and 2) neglecting the post peak behavior of the equivalent average resisting bond length's bond-based constitutive law in the evaluation of the strip's maximum effective capacity. The predictive performance of the formulation was appraised by considering some of the most recent experimental results available in literature. The formulation provided very satisfactory estimates of the experimental recordings, resulting the ratio of the prediction versus the experimental value characterized by a mean value and a standard deviation of 0.69 and 0.29 , respectively.

The proposed formulation was subsequently employed to carry out Monte Carlo simulations sampling, at each iteration, the value of each input parameter from the relevant uniform probability distribution and independently from each other. The results of those simulations were adopted in order to figure out which input parameters mostly affect the prediction of the NSM FRP strips shear strength contribution to a RC beam. From this sensitivity it arises that the input parameters that mostly affect the NSM shear strength contribution prediction are, in decreasing order of importance: $h_{w}, \alpha, f_{c m}$ and the CDC inclination angle $\theta$.

\section{Acknowledgements}

The authors of the present work wish to acknowledge the support provided by the "Empreiteiros Casais", $\mathrm{S} \& \mathrm{P} \otimes$, degussa ${ }^{\circledR}$ Portugal, and Secil (Unibetão, Braga). The study reported in this paper forms a part of the research program "PrePam", with reference number of PTDC/ECM/114511/2009, supported by FCT. Also, this work was 
carried out under the auspices of the Italian DPC-ReLuis Project (repertory n. 540), Research Line 8, whose financial support is greatly appreciated. 


\section{Notation}

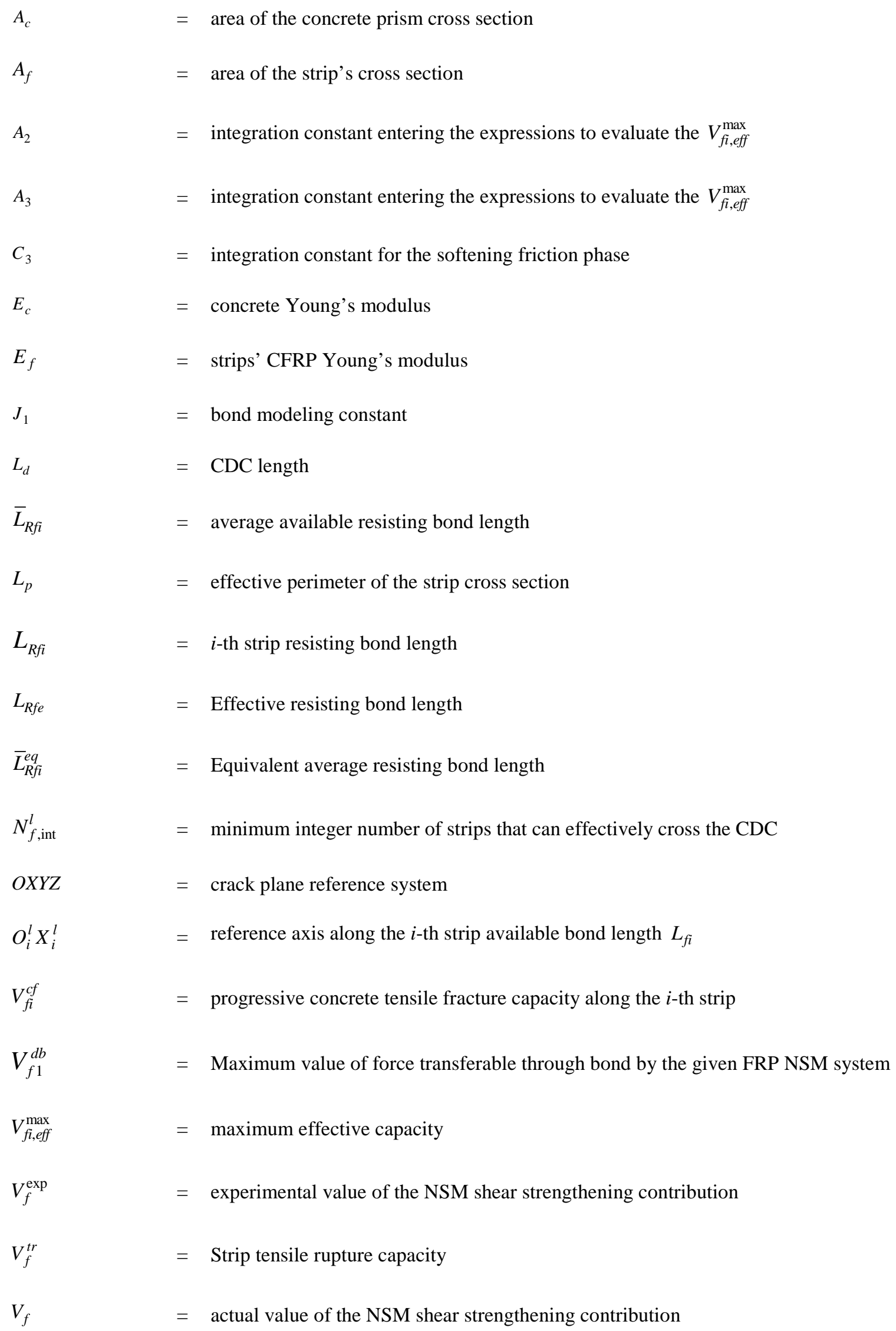




$$
\begin{aligned}
& V_{f d} \quad=\text { design value of the NSM shear strengthening contribution } \\
& V_{f i}\left(\bar{L}_{R f i} ; \delta_{L i}\right) \quad=\text { comprehensive constitutive law of the average available resisting bond length } \\
& V_{f i}^{b d}\left(\bar{L}_{R f i} ; \delta_{L i}\right) \quad=\quad \text { bond-based constitutive law of the average available resisting bond length } \\
& a_{f} \quad=\quad \text { strip cross section's thickness } \\
& b_{f} \quad=\quad \text { strip cross section's width } \\
& b_{w} \quad=\text { beam cross section's width } \\
& f_{c m} \quad=\text { concrete average cylindrical compressive strength } \\
& f_{c t m} \quad=\text { concrete average tensile strength } \\
& f_{c t m}^{*} \quad=\quad \begin{array}{l}
\text { Value of concrete average } \\
\text { fracture does not occur }
\end{array} \\
& f_{f u} \quad=\text { FRP tensile strength } \\
& h_{w} \quad=\text { beam web height } \\
& h_{f} \quad=\quad \text { vertical height of the NSM bar } \\
& s_{f} \quad=\quad \text { spacing between adjacent strips along the beam axis } \\
& \alpha \quad=\text { angle defining the concrete fracture surface } \\
& \beta \quad=\text { FRP strips inclination angle with respect to the beam longitudinal axis } \\
& \delta_{1}=\text { slip corresponding to the end of softening friction } \\
& \delta_{L i} \quad=\quad \text { imposed slip at the loaded extremity of the } i \text {-th strip } \\
& \delta_{L u}=\begin{array}{l}
\text { imposed slip in correspondence } \\
\text { transmissible by } \bar{L}_{R f i}^{e q} \text { is attained }
\end{array} \\
& \delta_{L 1}\left(V_{f}^{t r}\right) \quad=\quad \text { Value of imposed end slip in correspondence of which the strip tensile strength is } \\
& \delta_{L 1}\left(L_{R f i}\right)=\text { value of } \delta_{L i} \text { defining the end of the first phase of the bond-based constitutive law } \\
& \gamma_{\max }=\mathrm{CDC} \text { opening angle for which the maximum effective capacity is attained } \\
& \eta \quad=\quad \text { reduction factor of the initial average available resisting bond length } \\
& \gamma_{R d} \quad=\text { partial safety factor divisor of the capacity } \\
& \lambda=\text { constant entering the governing differential equation for elastic phase }
\end{aligned}
$$


$=$ critical Diagonal Crack $(\mathrm{CDC})$ inclination angle

$\theta^{\exp }$

$\tau(\delta)$

$\psi$

$\tau_{0}$
$=$ experimentally observed CDC inclination angle

$=$ local bond stress-slip relationship

Constant necessary to evaluate the maximum effective capacity provided by the equivalent average resisting bond length

$=$ adhesive-cohesive initial bond strength 


\section{References}

Ang, A., H-S, Tang, (1975), "Probability Concepts in Engineering Planning and Design - Volume I - Basic Principles”, John Wiley \& Sons, New York.

Ang, A., H-S, Tang, (1975), "Probability Concepts in Engineering Planning and Design - Volume II - Decision, Risk and Reliability”, John Wiley \& Sons, New York.

Bianco, V., Barros, J.A.O., Monti, G., (2009a). "Three dimensional mechanical model for simulating the NSM FRP strips shear strength contribution to RC beams”, Engineering Structures, 31(4), April 2009, 815-826.

Bianco, V., Barros, J.A.O., Monti, G., (2009b). "Bond Model of NSM FRP strips in the context of the Shear Strengthening of RC beams”, ASCE Journal of Structural Engineering, 135(6), June 2009.

Bianco, V., Barros, J.A.O., Monti, G., (2010). "New approach for modeling the contribution of NSM FRP strips for shear strengthening of RC beams", ASCE Journal of Composites for Construction, 14(1), January/February 2010.

Bianco, V., (2008). "Shear Strengthening of RC beams by means of NSM FRP strips: experimental evidence and analytical modeling”, PhD Thesis, Dept. of Structural Engrg. and Geotechnics, Sapienza University of Rome, Italy, submitted on December 2008.

Bianco, V., Monti, G., Barros, J.A.O., (2011). "Theoretical model and computational procedure to evaluate the NSM FRP strips shear strength contribution to a RC beam”, ASCE Journal of Structural Engineering, 137(11), November 2011.

Bousselham A., Chaalal O., (2004) "Shear Strengthening Reinforced Concrete Beams with Fiber-Reinforced Polymer: Assessment of Influencing Parameters and Required Research”, ACI Structural Journal, Vol.101, №2, March-April, pp. 219-227.

CEB-FIP Model Code 90, (1993) Bulletin d'Information $N^{\circ}$ 213/214, Final version printed by Th. Telford, London, (1993; ISBN 0-7277-1696-4; 460 pages).

Chao S.Y., Chen J.F., Teng J.G., Hao Z., Chen J., (2005) "Debonding in Reinforced Concrete Beams Shear Strengthened with Complete Fiber Reinforced Polymer Wraps”, Journal of Composites for Construction, ASCE September/October 2005/1.

Cisneros, D., Arteaga, A., De Diego, A., Alzate, A., Perera, R., (2012), “Experimental study on NSM FRP shear retrofitting of RC beams", $6^{\text {th }}$ international conference on Composites in Civil Engineering, CICE 2012, Rome, Italy, 13-15 June 2012. 
Dias, S.J.E. (2008). "Experimental and anlytical research in the shear strengthening of reinforced concreet beams using the near surface mounted technique with CFRP strips", PhD Thesis, Department of Civil Engineering, University of Minho, Guimarães-Portugal, in Portuguese.

Dias, S.J.E., Bianco, V., Barros, J.A.O., Monti, G., (2007). "Low strength concrete T cross section RC beams strengthened in shear by NSM technique", Workshop-Materiali ed Approcci Innovativi per il Progetto in Zona Sismica e la Mitigazione della Vulnerabilità delle Strutture, University of Salerno, Italy, 12-13 February.

Dias, S.J.E. and Barros, J.A.O., (2008). "Shear Strengthening of T Cross Section Reinforced Concrete Beams by Near Surface Mounted Technique”, Journal of Composites for Construction, ASCE, Vol. 12, No. 3, pp. 300311.

Draper, N.R., and Smith, H., (1966). “Applied Regression Analysis”, New York: John Wiley \& Sons, Inc. Chapter 6.

Islam, Anwarul, A.K.M., (2009). "Effective methods of using CFRP bars in shear strengthening of concrete girders”, Engineering Structures, 31(2009), 709-714.

Jalali, M., Sharbatdar, M.K., Chen, Jian-Fei, Alaee, Farshid Jandaghi, (2012), "Shear strengthening of RC beams using innovative manually made NSM FRP bars”, Construction and Building Materials, 36, 990-1000.

Law, A.M. and Kelton, W.D. Simulation Modeling and Analysis: McGraw-Hill, New York, NY, 1991,1982, 2000.

Monti, G., Renzelli, M., Luciani, P., (2003) "FRP Adhesion to Uncracked and Cracked Concrete Zones", Proceedings of the 6th International Symposium on Fibre-Reinforced Polymer (FRP) Reinforcement for Concrete Structures (FRPRCS-6), Singapore, July, 183-192.

Monti, G., Santinelli, F., Liotta, M.A., (2004) “Mechanics of FRP Shear Strengthening of RC beams”, Proc. ECCM 11, Rhodes, Greece.

Monti, G., Liotta, M.A., (2007) “Tests and design equations for FRP-strengthening in shear”, Construction and Building Materials (2006), 21(4), April 2007, 799-809.

Mohammed Ali, M.S., Oehlers, D.J., Seracino, R. (2006). "Vertical shear interaction model between external FRP transverse plates and internal stirrups", Engineering Structures 28, 381-389.

Mohammed Ali, M.S., Oehlers, D.J., Griffith, M.C., Seracino, R. (2007). "Interfacial stress transfer of near surface-mounted FRP-to-concrete joints”, Engineering Structures 30, 1861-1868.

Rahal, K.N., (2010). "Near surface mounted shear strengthening of reinforced concrete beams," American Concrete Institute, Special Publication SP-272-13, Oct. 2010, pp. 251-268 
Rahal, Khaldoun N., Rumaih, Hantem A., (2011), “Tests on reinforced concrete beams strengthened in shear using near surface mounted CFRP and steel bars", Engineering Structures, 33, 53-62.

Rizzo, A. and De Lorenzis, L., (2009) "Behaviour and capacity of Rc beams strengthened in shear with NSM FRP reinforcement”, Construction and Building Materials, Vol. 3, n. 4, April 2009, 1555-1567.

Sekulic, A., Curnier, A., (2006). “An original epoxy-stamp on glass-disc specimen exhibiting stable debonding for identifying adhesive properties between glass and epoxy", International Journal of Adhesion and Adhesives, Vol. 27, pp. 611-620.

Sena-Cruz, J.M., Barros, J.A.O., (2004). "Bond between near-surface mounted CFRP laminate strips and concrete in structural strengthening”, Journal of Composites for Construction, ASCE, Vol. 8, No. 6, pp. 519-527.

Yuan, H., Teng, J.G., Seracino, R., Wu, Z.S., Yao, J. (2004). "Full-range behavior of FRP-to-concrete bonded joints", Engineering Structures, 26, 553-565.

Zhai, L.L., Ling, G.P., Wang, Y.W., (2008). "Effect of nano- $\mathrm{Al}_{2} \mathrm{O}_{3}$ on adhesion strength of epoxy adhesive and steel”, International Journal of Adhesion and Adhesives, Vol. 28, No. 1-2, pp. 23-28. 


\section{TABLE CAPTIONS}

Table 1. Values of the parameters characterizing the beams tested by Dias and Barros (2008), Dias et al. (2007) and Dias (2008).

Table 2. Values of the parameters characterizing the beams tested by Rizzo and De Lorenzis (2009).

Table 3. Values of the parameters characterizing the beams tested by A.K.M. Anwarul Islam (2009).

Table 4. Values of the parameters characterizing the beams tested by Rahal and Rumaih (2011) and by Rahal (2010).

Table 5. Values of the parameters characterizing the beams tested by Jalali et al. (2012).

Table 6. Values of the parameters characterizing the beams tested by Cisneros et al. (2012).

Table 7. Values characterizing the uniform probability distribution of the input parameters.

Table 8. Detailed statistics of both the sampled values of input parameters and the calculated output. 
Table 1. Values of the parameters characterizing the beams tested by Dias and Barros (2008), Dias et al. (2007) and Dias (2008).

\begin{tabular}{|c|c|c|c|c|c|c|c|c|c|c|c|}
\hline $\begin{array}{l}\text { Beam } \\
\text { Label }\end{array}$ & $\begin{array}{c}\theta^{\exp } \\
\circ\end{array}$ & $\begin{array}{l}\beta \\
\text { 。 }\end{array}$ & $\begin{array}{l}s_{f} \\
m m\end{array}$ & $\begin{array}{c}\text { Steel } \\
\text { Stirrups }\end{array}$ & $\begin{array}{r}V_{f, 1}^{I} \\
k N\end{array}$ & $\begin{array}{r}V_{f, 2}^{I} \\
k N\end{array}$ & $\begin{array}{r}V_{f, 3}^{I} \\
k N\end{array}$ & $\begin{array}{l}V_{f}^{I I} \\
k N\end{array}$ & $\begin{array}{c}V_{f}^{\exp } \\
k N\end{array}$ & $\begin{array}{l}V_{f}^{I I I} \\
k N\end{array}$ & $V_{f}^{I I I} / V_{f}^{\exp }$ \\
\hline 2S-3LV-I & 40 & 90 & 267 & \begin{tabular}{|l|}
$6 / 300$ \\
\end{tabular} & 18.53 & 6.46 & 55.33 & 10.77 & 22.20 & 11.07 & 0.50 \\
\hline 2S-5LV-I & 40 & 90 & 160 & “ & 52.33 & 26.42 & 55.34 & 30.97 & 25.20 & 22.15 & 0.88 \\
\hline 2S-8LV-I & 36 & 90 & 100 & “ & 68.58 & 58.88 & 64.33 & 29.59 & 48.60 & 44.30 & 0.91 \\
\hline 2S-3LI45-I & 45 & 45 & 367 & “ & 35.10 & 15.41 & 45.73 & 23.44 & 29.40 & 16.00 & 0.54 \\
\hline 2S-5LI45-I & 45 & 45 & 220 & “ & 46.11 & 49.14 & 45.74 & 23.19 & 41.40 & 32.00 & 0.77 \\
\hline 2S-8LI45-I & 36 & 45 & 138 & “ & 75.89 & 79.71 & 78.73 & 59.55 & 40.20* & \begin{tabular}{|l|}
67.87 \\
\end{tabular} & 1.69 \\
\hline 2S-3LI60-I & 33 & 60 & 325 & “ & 50.69 & 18.90 & 51.68 & 30.74 & 35.40 & 12.88 & 0.36 \\
\hline 2S-5LI60-I & 36 & 60 & 195 & “ & 36.37 & 36.59 & 48.55 & 22.27 & 46.20 & 38.65 & 0.84 \\
\hline 2S-7LI60-I & 33 & 60 & 139 & “ & 52.98 & 63.07 & 67.58 & 60.80 & 54.60 & 51.53 & 0.94 \\
\hline 2S-7LV-II & 46 & 90 & 114 & \begin{tabular}{|l|l|}
$\phi 6 / 300$ \\
\end{tabular} & 26.72 & 31.84 & 35.59 & 15.04 & 28.32 & 13.19 & 0.47 \\
\hline 2S-4LI45-II & 40 & 45 & 275 & “ & 25.06 & 21.89 & 37.30 & 19.24 & 33.90 & 19.09 & 0.56 \\
\hline 2S-7LI45-II & 30 & 45 & 157 & “ & 49.36 & 47.13 & 45.95 & 37.92 & 48.00 & \begin{tabular}{|l|}
46.02 \\
\end{tabular} & 0.96 \\
\hline 2S-4LI60-II & 40 & 60 & 243 & “ & 21.31 & 15.04 & 29.38 & 13.23 & 33.06 & 15.35 & 0.46 \\
\hline 2S-6LI60-II & 27 & 60 & 162 & “ & 42.79 & 37.54 & 39.45 & 34.68 & 42.72 & 30.70 & 0.72 \\
\hline 4S-7LV-II & 46 & 90 & 114 & $\phi 6 / 180$ & \begin{tabular}{|l|}
26.72 \\
\end{tabular} & 31.84 & 35.59 & 15.04 & $6.90 *$ & 13.19 & 1.91 \\
\hline 4S-4LI45-II & 40 & 45 & 275 & “ & 25.06 & 21.89 & 37.30 & 19.24 & 26.04 & 19.09 & 0.73 \\
\hline 4S-7LI45-II & 40 & 45 & 157 & “ & 40.58 & 37.48 & 40.63 & 28.36 & 31.56 & 36.82 & 1.17 \\
\hline 4S-4LI60-II & 40 & 60 & 243 & “ & 21.31 & 15.04 & 29.38 & 13.23 & 25.08 & 15.35 & 0.61 \\
\hline 4S-6LI60-II & 30 & 60 & 162 & “ & 38.92 & 35.46 & 36.71 & 25.72 & 35.10 & 30.70 & 0.87 \\
\hline 3S-5LI45-III & 30 & 45 & 275 & \begin{tabular}{|c|}
$\phi 6 / 300$ \\
\end{tabular} & 59.74 & 59.55 & 70.01 & 70.33 & 66.10 & 54.03 & 0.82 \\
\hline 3S-5LI45F1-III ${ }^{* *}$ & 23 & 45 & 275 & “ & 83.05 & 86.96 & 81.15 & 77.93 & 85.75 & 81.05 & 0.95 \\
\hline 3S-5LI45F2-III ${ }^{* *}$ & 30 & 45 & 275 & “ & 59.74 & 59.55 & 70.01 & 70.33 & 65.35 & \begin{tabular}{|l|}
54.03 \\
\end{tabular} & 0.83 \\
\hline 5S-5LI45-III & 28 & 45 & 275 & $\$ 6 / 200$ & 78.24 & 59.55 & 72.01 & 57.76 & 74.90 & 81.05 & 1.08 \\
\hline 5S-5LI45F-III ${ }^{* *}$ & 28 & 45 & 275 & “ & 78.24 & 59.55 & 72.01 & 57.76 & 74.90 & 81.05 & 1.08 \\
\hline 3S-9LI45-III & 32 & 45 & 157 & $\phi 6 / 300$ & 109.88 & 109.32 & 98.30 & 114.30 & 101.85 & 104.27 & 1.02 \\
\hline 5S-9LI45-III & 32 & 45 & 157 & $\$ 6 / 200$ & 109.88 & 109.32 & 98.30 & 114.30 & 108.90 & 104.27 & 0.96 \\
\hline 3S-5LI60-III & 26 & 60 & 243 & $\$ 6 / 300$ & 71.74 & 76.20 & 62.81 & 52.84 & 69.00 & \begin{tabular}{|l|}
65.61 \\
\end{tabular} & 0.95 \\
\hline 5S-5LI60-III & 25 & 60 & 243 & $\phi 6 / 200$ & 68.48 & 77.44 & 63.79 & 59.82 & 73.35 & \begin{tabular}{|l|}
65.61 \\
\end{tabular} & 0.89 \\
\hline 5S-5LI60F-III** & 25 & 60 & 243 & “ & 68.48 & 77.44 & 63.79 & 59.82 & 72.55 & 65.61 & 0.90 \\
\hline 3S-8LI60-III & 22 & 60 & 162 & $\$ 6 / 300$ & 112.82 & 119.58 & 112.25 & 109.30 & 112.30 & 109.35 & 0.97 \\
\hline 5S-8LI60-III & 19 & 60 & 162 & $\phi 6 / 200$ & 123.34 & 122.74 & 132.00 & 114.69 & 122.45 & 131.22 & 1.07 \\
\hline 3S-6LV-III & 45 & 90 & 180 & $\phi 6 / 300$ & 58.24 & 26.62 & 66.53 & 35.04 & 39.58 & 18.83 & 0.48 \\
\hline 3S-10LV-III & 32 & 90 & 114 & “ & 97.50 & 82.41 & 85.21 & 60.23 & 83.25 & \begin{tabular}{|l|}
75.34 \\
\end{tabular} & 0.90 \\
\hline
\end{tabular}

* beams whose experimental value of NSM shear strength contribution is affected by some disturbance;

** beams that were subjected to pre-cracking. 
Table 2. Values of the parameters characterizing the beams tested by Rizzo and De Lorenzis (2009).

\begin{tabular}{|c|c|c|c|c|c|c|c|c|c|c|c|c|c|c|c|}
\hline $\begin{array}{c}\text { Beam } \\
\text { Label }\end{array}$ & $\begin{array}{c}\boldsymbol{\theta} \\
\circ\end{array}$ & $\begin{array}{c}\beta \\
\circ\end{array}$ & $\begin{array}{c}s_{f} \\
\mathrm{~mm}\end{array}$ & $\begin{array}{c}f_{f u} \\
\mathrm{GPa}\end{array}$ & $\begin{array}{c}E_{f} \\
G P a\end{array}$ & $\begin{array}{c}a_{f} \\
m m\end{array}$ & $\begin{array}{c}b_{f} \\
m m\end{array}$ & $\begin{array}{c}\phi_{f} \\
m m\end{array}$ & $\begin{array}{c}V_{f, 1}^{I} \\
k N\end{array}$ & $\begin{array}{c}V_{f, 2}^{I} \\
k N\end{array}$ & $\begin{array}{c}V_{f, 3}^{I} \\
k N\end{array}$ & $\begin{array}{c}V_{f}^{I I} \\
k N\end{array}$ & $\begin{array}{c}V_{f}^{\exp } \\
k N\end{array}$ & $\begin{array}{c}V_{f} \\
k N\end{array}$ & $V_{f} / V_{f}^{\exp }$ \\
\hline \hline NB90-73-a-IV & 45 & 90 & 73 & 2.21 & 145.7 & - & - & 8 & 24.84 & 27.01 & 33.73 & 11.59 & $\mathbf{5 4 . 2 0}$ & $\mathbf{1 0 . 0 8}$ & $\mathbf{0 . 1 9}$ \\
\hline NB90-73b-IV & 45 & 90 & 73 & $“$ & $\cdots$ & - & - & $\cdots$ & 24.84 & 27.01 & 33.73 & 11.59 & $\mathbf{2 6 . 4 0}$ & $\mathbf{1 0 . 0 8}$ & $\mathbf{0 . 3 8}$ \\
\hline NB90-45-b-IV & 45 & 90 & 45 & $\cdots$ & $\cdots$ & - & - & $\cdots$ & 35.86 & 31.77 & 38.87 & 16.99 & $\mathbf{2 8 . 6 0}$ & $\mathbf{1 5 . 9 2}$ & $\mathbf{0 . 5 6}$ \\
\hline NB45-146-a-IV & 45 & 45 & 146 & $\cdots$ & $\cdots$ & - & - & $\cdots$ & 25.50 & 24.69 & 24.69 & 17.68 & $\mathbf{3 9 . 1 0}$ & $\mathbf{1 4 . 3 1}$ & $\mathbf{0 . 3 7}$ \\
\hline NB45-73-a-IV & 45 & 45 & 73 & $\cdots$ & $\cdots$ & - & - & $\cdots$ & 37.69 & 34.06 & 38.86 & 19.54 & $\mathbf{2 8 . 0 0}$ & $\mathbf{2 2 . 9 1}$ & $\mathbf{0 . 8 2}$ \\
\hline \hline NS90-73-a-IV & 45 & 90 & 73 & 2.07 & 121.5 & 2.0 & 16.0 & - & 21.39 & 23.98 & 34.24 & 12.93 & $\mathbf{5 0 . 5 0}$ & $\mathbf{1 0 . 1 6}$ & $\mathbf{0 . 2 0}$ \\
\hline NS45-146-a-IV & 45 & 45 & 146 & $\cdots$ & $\cdots$ & $\cdots$ & $\cdots$ & - & 27.76 & 27.87 & 34.33 & 14.09 & $\mathbf{3 2 . 7 0}$ & $\mathbf{1 4 . 5 3}$ & $\mathbf{0 . 4 4}$ \\
\hline
\end{tabular}

$b_{w} 200 \mathrm{~mm} ; h_{w} 210 \mathrm{~mm} ; f_{c m} 29.3 \mathrm{MPa}$; steel stirrups $\phi 6 / 160$; 
Table 3. Values of the parameters characterizing the beams tested by A.K.M. Anwarul Islam (2009).

\begin{tabular}{|c|c|c|c|c|c|c|c|c|c|c|c|c|c|}
\hline $\begin{array}{c}\text { Beam } \\
\text { Label }\end{array}$ & $\theta$ & $\beta$ & $s_{f}$ & $\begin{array}{c}\text { Steel } \\
\mathrm{o} m\end{array}$ & $\begin{array}{c}f_{f u} \\
\text { Stirrups }\end{array}$ & $\begin{array}{c}E_{f} \\
G P a\end{array}$ & $\begin{array}{c}V_{f, 1}^{I} \\
k P a\end{array}$ & $\begin{array}{c}V_{f, 2}^{I} \\
k N\end{array}$ & $\begin{array}{c}V_{f, 3}^{I} \\
k N\end{array}$ & $\begin{array}{c}V_{f}^{I I} \\
k N\end{array}$ & $\begin{array}{c}V_{f}^{\exp } \\
k N\end{array}$ & $\begin{array}{c}V_{f} \\
k N\end{array}$ & $V_{f} / V_{f}^{\exp }$ \\
\hline \hline B2-FRP-V & 45 & 90 & 152 & - & 2.07 & 124 & 77.16 & 43.65 & 77.57 & 28.98 & $\mathbf{4 4 . 5 0}$ & $\mathbf{3 3 . 4 4}$ & $\mathbf{0 . 7 5}$ \\
\hline B-3-FRP-V & 45 & 90 & 305 & $\phi 9 / 305$ & 2.07 & 124 & 0.00 & 0.00 & 77.11 & 1.16 & $\mathbf{3 1 . 0 0}$ & $\mathbf{1 6 . 7 2}$ & $\mathbf{0 . 5 4}$ \\
\hline B-4-FRP-V & 45 & 90 & 191 & $\phi 9 / 610$ & 2.07 & 124 & 49.76 & 28.79 & 77.53 & 37.26 & $\mathbf{3 5 . 5 0}$ & $\mathbf{1 6 . 7 2}$ & $\mathbf{0 . 4 7}$ \\
\hline
\end{tabular}


Table 4. Values of the parameters characterizing the beams tested by Rahal and Rumaih (2011) and by Rahal (2010).

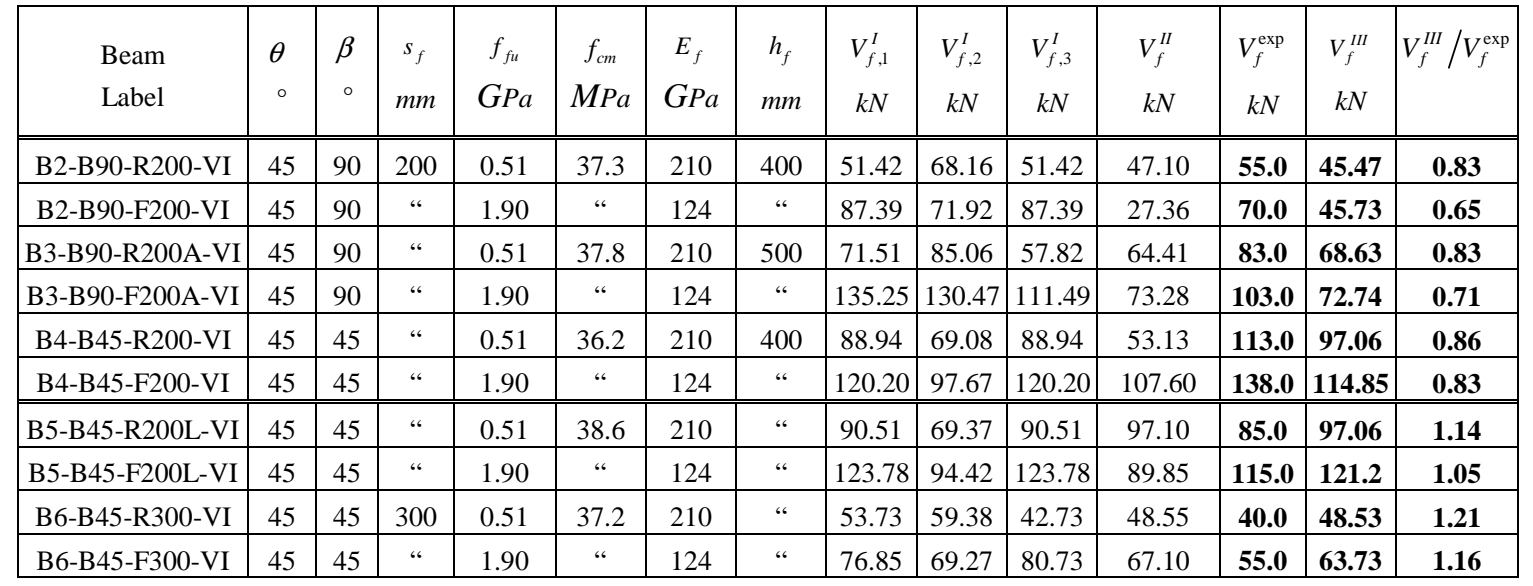

$\phi_{f}$ equal to $8 \mathrm{~mm} ; b_{w}$ equal to $150 \mathrm{~mm}$; steel stirrups equal to $\phi 6 / 200$; 
Table 5. Values of the parameters characterizing the beams tested by Jalali et al. (2012).

\begin{tabular}{|c|c|c|c|c|c|c|c|c|c|c|c|c|c|}
\hline $\begin{array}{l}\text { Beam } \\
\text { Label }\end{array}$ & $\begin{array}{l}\theta \\
\circ\end{array}$ & $\begin{array}{l}\beta \\
\circ\end{array}$ & $\begin{array}{c}s_{f} \\
m m\end{array}$ & $\begin{array}{c}\text { Steel } \\
\text { Stirrups }\end{array}$ & $\begin{array}{c}f_{f u} \\
G P a\end{array}$ & $\begin{array}{c}E_{f} \\
G P a\end{array}$ & $\begin{array}{l}V_{f, 1}^{I} \\
k N\end{array}$ & $\begin{array}{c}V_{f, 2}^{I} \\
k N\end{array}$ & $\begin{array}{c}V_{f, 3}^{I} \\
k N\end{array}$ & $\begin{array}{l}V_{f}^{I I} \\
k N\end{array}$ & $\begin{array}{c}V_{f}^{\exp } \\
k N\end{array}$ & $\begin{array}{l}V_{f} \\
k N\end{array}$ & $V_{f} / V_{f}^{\exp }$ \\
\hline VR-VII & 45 & 90 & 160 & $\phi 6 / 150$ & 3.55 & 235 & 28.18 & 10.65 & 52.28 & 12.5 & 33.41 & 8.65 & 0.26 \\
\hline IR-VII & 45 & 45 & 240 & “ & “ & “ & 43.36 & 25.69 & 35.85 & 19.94 & $\mathbf{5 3 . 9 4}$ & 24.54 & 0.45 \\
\hline VRA-VII & 45 & 90 & 160 & " & " & " & 28.18 & 10.65 & 52.28 & 12.5 & 39.88 & 8.65 & 0.22 \\
\hline IRA-VII & 45 & 45 & 240 & “ & “ & “ & 43.36 & 25.69 & 35.85 & 19.94 & 63.82 & 24.54 & 0.38 \\
\hline VRA-VII & 45 & 90 & 160 & “ & " & " & 28.18 & 10.65 & 52.28 & 12.5 & 29.4 & 8.65 & 0.29 \\
\hline
\end{tabular}


Table 6. Values of the parameters characterizing the beams tested by Cisneros et al. (2012).

\begin{tabular}{|c|c|c|c|c|c|c|c|c|c|c|c|c|c|c|c|}
\hline $\begin{array}{l}\text { Beam } \\
\text { Label }\end{array}$ & $\begin{array}{l}\theta \\
\circ\end{array}$ & $\begin{array}{l}\beta \\
\circ\end{array}$ & $\begin{array}{c}s_{f} \\
m m\end{array}$ & $\begin{array}{c}\text { Steel } \\
\text { Stirrups }\end{array}$ & $\begin{array}{c}f_{c m} \\
M P a\end{array}$ & $\begin{array}{c}a_{f} \\
m m\end{array}$ & $\begin{array}{c}b_{f} \\
m m\end{array}$ & $\begin{array}{c}\phi_{f} \\
m m\end{array}$ & $\begin{array}{r}V_{f, 1}^{I} \\
k N\end{array}$ & $\begin{array}{c}V_{f, 2}^{I} \\
k N\end{array}$ & $\begin{array}{r}V_{f, 3}^{I} \\
k N\end{array}$ & $\begin{array}{l}V_{f}^{I I} \\
k N\end{array}$ & $\begin{array}{c}V_{f}^{\exp } \\
k N\end{array}$ & $\begin{array}{l}V_{f} \\
k N\end{array}$ & $V_{f} / V_{f}^{\exp }$ \\
\hline B90-6a-VIII & 45 & 90 & 115 & $\phi 6 / 150$ & 26.69 & - & - & 8 & 35.91 & 36.04 & 55.17 & 20.50 & $\mathbf{5 8 . 3 0}$ & 18.91 & 0.32 \\
\hline B90-6b-VIII & “ & “ & “" & “ & 24.09 & - & - & “ & 33.03 & 34.53 & 50.28 & 19.88 & 55.00 & 17.12 & 0.31 \\
\hline B90-3a-VIII & " & " & 230 & “ & 22.84 & - & - & " & 12.07 & 3.69 & 45.79 & 8.66 & 11.00 & 8.11 & 0.74 \\
\hline B90-3b-VIII & “ & “ & “" & “ & 26.02 & - & - & “ & 12.96 & 4.55 & 51.54 & 9.22 & 6.30 & 9.23 & 1.47 \\
\hline B45-6a-VIII & “ & 45 & 115 & “ & 22.98 & - & - & “ & 44.14 & 44.90 & 49.52 & 37.05 & 74.20 & 41.02 & 0.55 \\
\hline B45-6b-VIII & “ & “ & “ & “ & 28.48 & - & - & “ & 56.03 & 57.10 & 62.56 & 50.34 & 98.20 & 50.52 & 0.51 \\
\hline B45-3a-VIII & “ & “ & 230 & “ & 29.11 & - & - & “ & 35.29 & 36.87 & 51.88 & 26.84 & 40.20 & 29.19 & 0.73 \\
\hline B45-3b-VIII & “ & “ & “ & “ & 23.91 & - & - & “ & 31.22 & 35.24 & 53.06 & 19.04 & 81.00 & 24.18 & 0.30 \\
\hline S90-6a-VIII & “ & 90 & 115 & “ & 26.69 & 2.5 & 15.0 & - & 34.52 & 36.51 & 55.37 & 16.90 & 75.80 & 19.05 & 0.25 \\
\hline S90-6b-VIII & “ & “ & " & “ & 24.09 & “ & “ & - & 34.03 & 37.66 & 58.26 & 21.77 & 38.90 & 17.24 & 0.44 \\
\hline S90-3a-VIII & “ & “ & 230 & “" & 22.84 & “" & “ & - & 13.96 & 5.36 & 57.37 & 9.24 & 10.50 & 8.17 & 0.78 \\
\hline S90-3b-VIII & “ & “ & “ & “" & 26.02 & “ & “ & - & 15.66 & 5.84 & 55.34 & 7.80 & 20.40 & 9.3 & 0.46 \\
\hline S45-6a-VIII & “ & 45 & 115 & “ & 22.98 & “ & “ & - & 54.24 & 52.13 & 54.22 & 31.96 & 77.10 & 41.63 & 0.54 \\
\hline S45-6b-VIII & “ & “ & “ & “ & 28.48 & “ & “ & - & 58.79 & 56.21 & 72.10 & 45.82 & 106.40 & 51.27 & 0.48 \\
\hline S45-3a-VIII & “ & “ & 230 & “ & 29.11 & “ & “ & - & 37.34 & 45.79 & 50.38 & 35.33 & 58.10 & 29.62 & 0.51 \\
\hline S45-3b-VIII & “ & “ & “ & “ & 23.91 & “ & “ & - & 45.29 & 32.39 & 50.97 & 31.68 & 98.00 & 24.54 & 0.25 \\
\hline
\end{tabular}

$f_{f u} 2.5 \mathrm{GPa} ; E_{f} 165 \mathrm{GPa} ; b_{w} 200 \mathrm{~mm} ; h_{w} 300 \mathrm{~mm} ;$ 
Table 7. Values characterizing the uniform probability distribution of the input parameters.

\begin{tabular}{|c|c|c|c|c|c|c|c|c|c|c|c|c|c|}
\hline & $\begin{array}{c}\theta \\
\circ\end{array}$ & $\begin{array}{c}h_{w} \\
m m\end{array}$ & $\begin{array}{c}b_{w} \\
m m\end{array}$ & $\begin{array}{c}a_{f} \\
m m\end{array}$ & $\begin{array}{c}b_{f} \\
m m\end{array}$ & $\begin{array}{c}s_{f} \\
m m\end{array}$ & $\begin{array}{c}\beta \\
\circ\end{array}$ & $\begin{array}{c}E_{f} \\
G P a\end{array}$ & $\begin{array}{c}f_{f u} \\
G P a\end{array}$ & $\begin{array}{c}f_{c m} \\
M P a\end{array}$ & $\underset{\circ}{\alpha}$ & $\begin{array}{c}\tau_{0} \\
M P \\
a\end{array}$ & $\begin{array}{c}\delta_{1} \\
m m\end{array}$ \\
\hline Range of variation & $\begin{array}{c}20- \\
60\end{array}$ & $\begin{array}{c}300- \\
700\end{array}$ & $\begin{array}{c}150- \\
400\end{array}$ & $\begin{array}{l}1.0- \\
5.5\end{array}$ & $\begin{array}{l}5- \\
35\end{array}$ & $\begin{array}{l}50- \\
250\end{array}$ & $\begin{array}{c}45- \\
90\end{array}$ & $\begin{array}{l}100- \\
200\end{array}$ & $\begin{array}{l}1.0- \\
6.0\end{array}$ & $\begin{array}{l}10- \\
90\end{array}$ & $\begin{array}{l}10- \\
35\end{array}$ & $\begin{array}{l}10- \\
30\end{array}$ & $\begin{array}{l}2.0- \\
15.0\end{array}$ \\
\hline
\end{tabular}


Table 8. Detailed statistics of both the sampled values of input parameters and the calculated output.

\begin{tabular}{|c||c|c||c||c|c||c|c|c|c|c|c||c|c||c|c|}
\hline & $\begin{array}{c}V_{f i, e f f}^{\max } \\
\mathrm{kN}\end{array}$ & $\begin{array}{c}V_{f} \\
\mathrm{kN}\end{array}$ & $\begin{array}{c}\theta \\
\circ\end{array}$ & $\begin{array}{c}h_{w} \\
m m\end{array}$ & $\begin{array}{c}b_{w} \\
m m\end{array}$ & $\begin{array}{c}a_{f} \\
m m\end{array}$ & $\begin{array}{c}b_{f} \\
m m\end{array}$ & $\begin{array}{c}s_{f} \\
m m\end{array}$ & $\begin{array}{c}\beta \\
\circ\end{array}$ & $\begin{array}{c}E_{f} \\
G P a\end{array}$ & $\begin{array}{c}f_{f u} \\
G P a\end{array}$ & $\begin{array}{c}f_{c m} \\
M P a\end{array}$ & $\begin{array}{c}\alpha \\
\circ\end{array}$ & $\begin{array}{c}\tau_{0} \\
M P a\end{array}$ & $\begin{array}{c}\delta_{1} \\
m m\end{array}$ \\
\hline Minimum & 0.16 & 0 & 20.0 & 300.0 & 150.0 & 1.0 & 5.0 & 50.0 & 45.0 & 100.0 & 1.0 & 10.0 & 10.0 & 10.0 & 2.0 \\
\hline Maximum & 123.42 & 1886.39 & 59.99 & 699.99 & 399.99 & 5.49 & 34.99 & 249.99 & 89.99 & 199.99 & 5.99 & 89.99 & 35.0 & 29.99 & 14.99 \\
\hline Mean & 14.63 & 163.66 & 40.03 & 499.21 & 275.19 & 3.25 & 20.01 & 149.93 & 67.51 & 149.90 & 3.50 & 49.98 & 22.5 & 19.99 & 8.51 \\
\hline $\begin{array}{c}\text { Standard } \\
\text { Deviation }\end{array}$ & 12.77 & 172.13 & 11.55 & 115.35 & 72.21 & 1.29 & 8.63 & 57.79 & 12.98 & 28.92 & 1.44 & 23.11 & 7.22 & 5.78 & 3.75 \\
\hline
\end{tabular}




\section{FIGURE CAPTIONS}

Fig. 1. Main physical-mechanical features of the theoretical model and calculation procedure: a) average-available-bond-length NSM strip and concrete prism of influence, b) adopted local bond stress-slip relationship, c) NSM strip confined to the corresponding concrete prism of influence and semi-pyramidal fracture surface, d) sections of the concrete prism.

Fig. 2. Further simplifying assumptions introduced: a) reduction of the available average resisting bond length due to progressive concrete fracture, b) available length reduction factor as function of the concrete average tensile strength, c) bond-based constitutive law for NSM FRP strips with different values of resisting bond length, d) assumed comprehensive constitutive law of the equivalent average available resisting bond length strip.

Fig. 3. Calculation procedure: main algorithm.

Fig. 4. Results of the Monte Carlo simulations: probability density distribution, cumulated probability distribution and mapped regression coefficients for a) the NSM FRP strips shear strength contribution $V_{f}$, and b) the average strip maximum effective capacity $V_{f i, e f f}^{\max }$.

Fig. A1. Evaluation of the average available resisting bond length $\bar{L}_{R f i}$. 


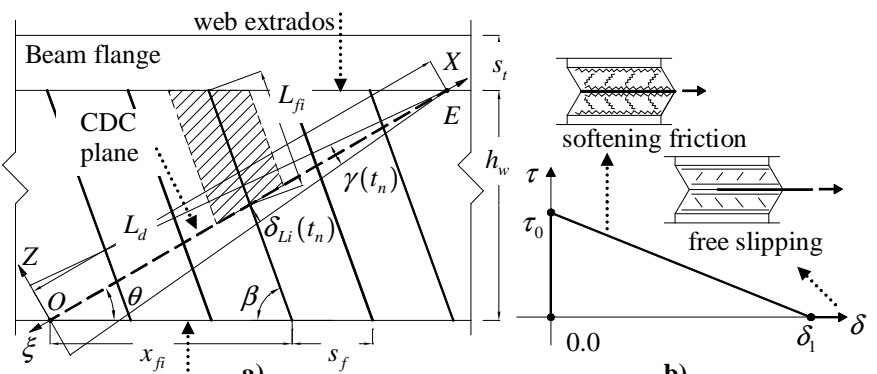

b)

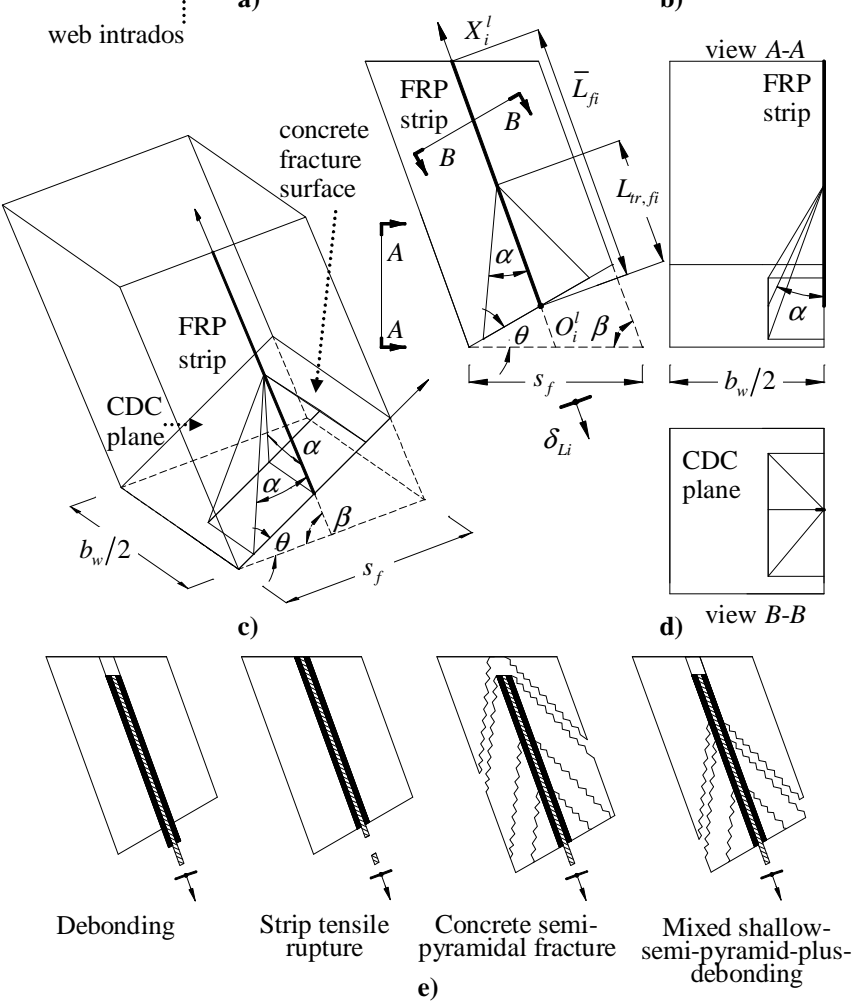

Fig. 1. Main physical-mechanical features of the theoretical model and calculation procedure: a) average-available-bond-length NSM strip and concrete prism of influence, b) adopted local bond stress-slip relationship, c) NSM strip confined to the corresponding concrete prism of influence and semi-pyramidal fracture surface, d) sections of the concrete prism. 


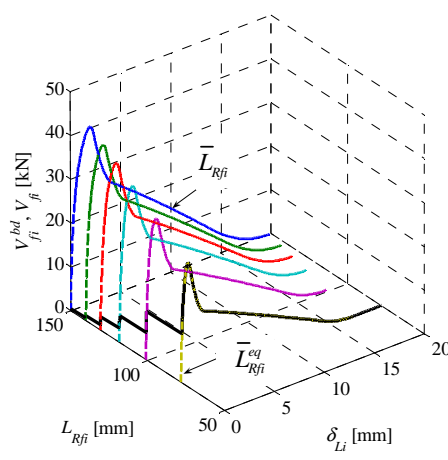

a)

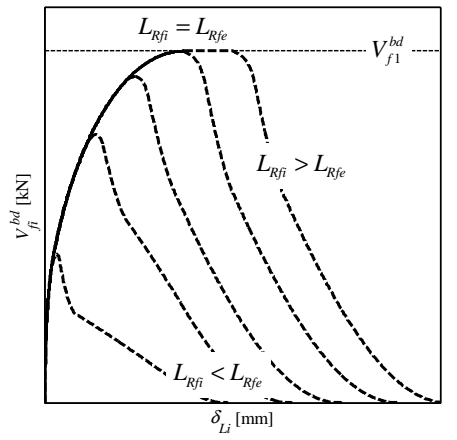

c)

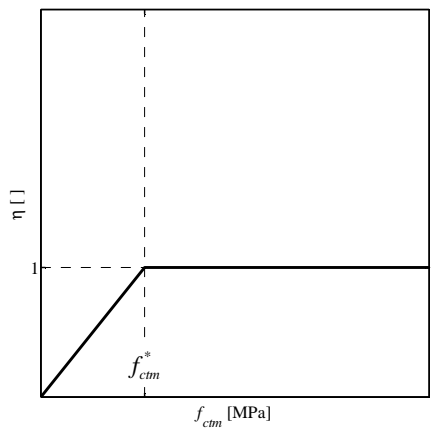

b)

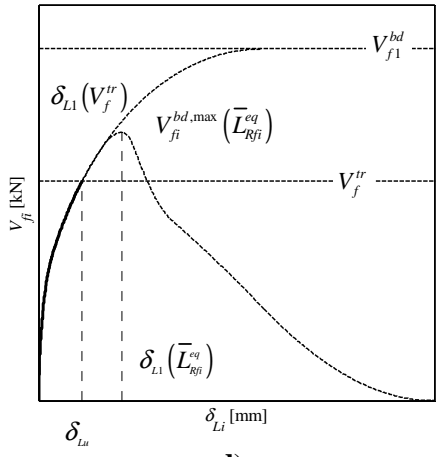

d)

Fig. 2. Further simplifying assumptions introduced: a) reduction of the available average resisting bond length due to progressive concrete fracture, b) available length reduction factor as function of the concrete average tensile strength, c) bond-based constitutive law for NSM FRP strips with different values of resisting bond length, d) assumed comprehensive constitutive law of the equivalent average available resisting bond length strip. 


\begin{tabular}{|c|}
\hline $\begin{array}{c}\text { Input Parameters } \\
h_{w} ; b_{w} ; \alpha ; f_{c m} ; s_{f} ; \beta ; f_{f u} ; E_{f} ; a_{f} ; b_{f} ; \tau_{0} ; \delta_{1} ; \theta\end{array}$ \\
\hline $\begin{array}{l}\text { Evaluation of the average available resisting bond length and the minimum } \\
\text { integer number of FRP strips effectively crossing the CDC } \\
\qquad \bar{L}_{R f i}=f\left(h_{w} ; \theta ; \beta ; s_{f}\right) ; N_{f, \text { int }}^{l}\end{array}$ \\
\hline $\begin{array}{c}\text { Evaluation of various constants } \\
L_{p} ; A_{c} ; V_{f}^{t r} ; V_{f 1}^{b d} ; J_{1} ; \lambda ; C_{3}\end{array}$ \\
\hline $\begin{array}{l}\text { Evaluation of the average available resisting bond length reduction factor } \\
\text { and the equivalent average resisting bond length } \\
\qquad \eta\left(s_{f} ; b_{w} ; f_{c t m} ; \bar{L}_{R f i}\right) ; \bar{L}_{R f i}^{e q}\end{array}$ \\
\hline $\begin{array}{l}\text { Evaluation of the value of imp. end slip for which the peak force transferable } \\
\text { through bond is attained, also accounting for the possibility of strip rupture } \\
\delta_{L u}\end{array}$ \\
\hline $\begin{array}{c}\text { Evaluation of the maximum effective capacity attainable } \\
V_{f i, e f f}^{\max }\end{array}$ \\
\hline $\begin{array}{l}\text { Evaluation of the NSM FRP strips shear strength contribution } \\
\qquad V_{f d}^{\max }=\frac{1}{\gamma_{R d}} \cdot 2 \cdot N_{f, \text { int }}^{l} \cdot V_{f i, e f f}^{\max } \cdot \sin \beta\end{array}$ \\
\hline
\end{tabular}

Fig. 3. Calculation procedure: main algorithm. 

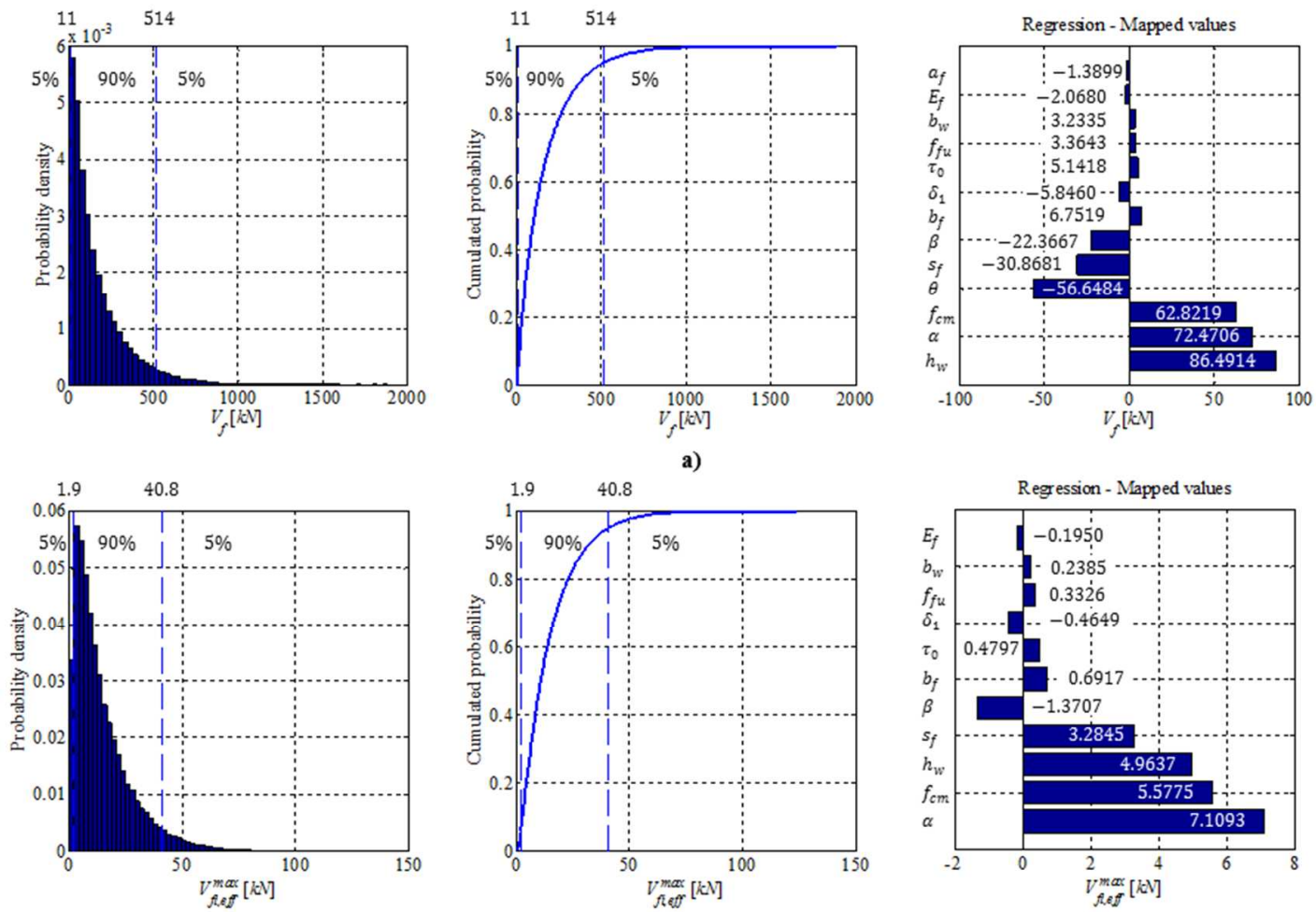

b)

Fig. 4. Results of the Monte Carlo simulations: probability density distribution, cumulated probability distribution and mapped regression coefficients for a) the NSM FRP strips shear strength contribution $V_{f}$, and b) the average strip maximum effective capacity $V_{f i, e f f}^{\max }$. 


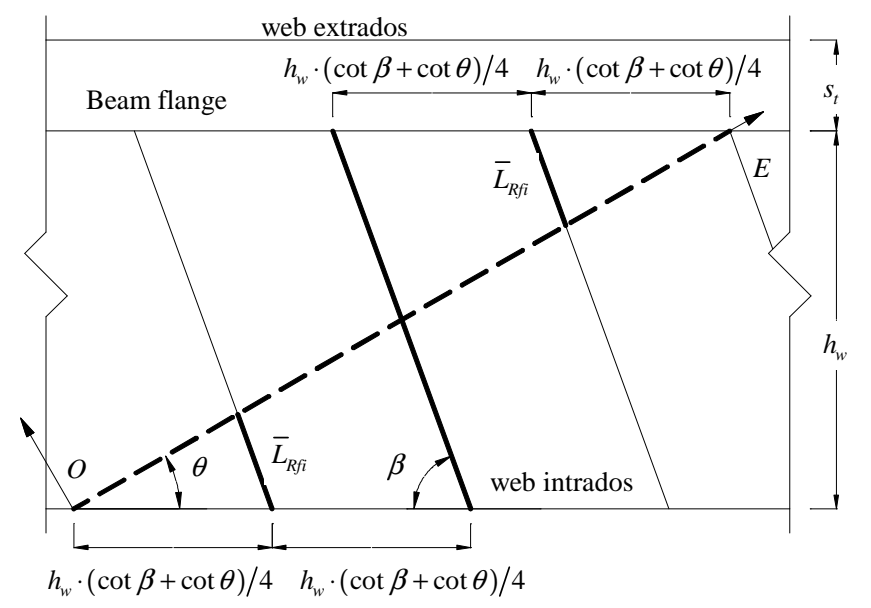

Fig. A1. Evaluation of the average available resisting bond length $\bar{L}_{R f i}$. 


\section{APPENDIX}

The average available resisting bond length herein is no longer evaluated as the average of the available resisting bond length $\bar{L}_{f i}=\sum_{i=1}^{N_{f, \text {,int }}^{l}} L_{f i} / N_{f, \text { int }}^{l}$ of all the $N_{f \text {,int }}^{l}$ strips effectively bridging the CDC, as done in the previous work (Bianco et al. 2011). In an attempt to gain simplicity, without losing accuracy, $\bar{L}_{f i}$, herein designated as $\bar{L}_{R f i}$ , is evaluated as the actual average value that a strip effectively intersecting the CDC can attain, independently of either the actual number of strips and their location along the CDC. According to the approach schematically represented in Fig. A1, $\bar{L}_{R f i}$ is evaluated by applying the sine theorem to the smallest triangle, i.e.: $\frac{\bar{L}_{R f i}}{\sin \theta}=\frac{h_{w} \cdot(\cot \theta+\cot \beta)}{4 \cdot \sin [\pi-(\theta+\beta)]}$ from which Eq. (1) can be derived.

Once the value of the equivalent average resisting bond length $\bar{L}_{R f i}^{e q}$ is evaluated, the relevant bond-based constitutive law $V_{f i}^{b d}\left(\bar{L}_{R f i}^{e q} ; \delta_{L i}\right)$ is considered neglecting the post-peak branch thus reducing, with respect to what was done in the previous work (Bianco et al. 2011), to:

$$
V_{f i}^{b d}\left(\bar{L}_{R f i}^{e q} ; \delta_{L i}\right)=L_{p} \cdot J_{3} \cdot \lambda \cdot\left\{C_{1}^{s f} \cdot\left[\cos \left(\lambda \cdot L_{t r}^{s f}\left(\delta_{L i}\right)\right)-1\right]-C_{2}^{s f} \cdot \sin \left(\lambda \cdot L_{t r}^{s f}\left(\delta_{L i}\right)\right)\right\}
$$

To evaluate the value of imposed end slip in correspondence of which the force transferred through bond equals the strip rupture capacity $V_{f}^{t r}$, the $V_{f i}^{b d}\left(\bar{L}_{R f i}^{e q} ; \delta_{L i}\right)$ in the previous equations is replaced by $V_{f}^{t r}$ :

$$
\frac{V_{f}^{t r}}{L_{p} \cdot J_{3} \cdot \lambda}=\cdot\left\{C_{1}^{s f} \cdot\left[\cos \left(\lambda \cdot L_{t r}^{s f}\left(\delta_{L i}\right)\right)-1\right]-C_{2}^{s f} \cdot \sin \left(\lambda \cdot L_{t r}^{s f}\left(\delta_{L i}\right)\right)\right\}
$$

that can be rewritten as:

$$
C_{1}^{s f} \cdot \cos \left(\lambda \cdot L_{t r}^{s f}\right)-C_{2}^{s f} \cdot \sin \left(\lambda \cdot L_{t r}^{s f}\right)=\frac{V_{f}^{t r}}{L_{p} \cdot J_{3} \cdot \lambda}+C_{1}^{s f}=C_{3}^{s f}
$$

in which $L_{t r}^{s f}\left(\delta_{L i}\right)$ was indicated, for the sake of brevity, as $L_{t r}^{s f}$. Moreover, since in the present work the superscript $s f$ referring to the softening friction bond fase is neglected, the previous equation is reduced to:

$$
C_{1} \cdot \cos \left(\lambda \cdot L_{t r}\right)-C_{2} \cdot \sin \left(\lambda \cdot L_{t r}\right)=\frac{V_{f}^{t r}}{L_{p} \cdot J_{3} \cdot \lambda}+C_{1}=C_{3}
$$


This equation, in which the unknown is $\delta_{L 1}\left(V_{f}^{t r}\right)$ that is the value of $\delta_{L i}$ such that $V_{f i}^{b d}\left(\bar{L}_{R f i}^{e q} ; \delta_{L i}\right)=V_{f}^{t r}$, is solved as follows: each term is firstly divided by $\sqrt{C_{1}^{2}+C_{2}^{2}}$ and then the position in made in which $C_{1} / \sqrt{C_{1}^{2}+C_{2}^{2}}=\sin \varphi$ and $C_{2} / \sqrt{C_{1}^{2}+C_{2}^{2}}=\cos \varphi$, yielding:

$$
\frac{C_{3}}{\sqrt{C_{1}^{2}+C_{2}^{2}}}=\sin \left(\varphi-\lambda \cdot L_{t r}\right)
$$

From this latter, one obtains:

$$
L_{t r}=\frac{1}{\lambda} \cdot\left[\varphi-\arcsin \frac{C_{3}}{\sqrt{C_{1}^{2}+C_{2}^{2}}}\right]
$$

Introducing in this latter the expression the dependence of $L_{t r}$ on $\delta_{L i}$, given by Eq. (6.1) of the previous work (Bianco et al. 2011) the following equation is derived:

$$
\frac{1}{\lambda} \cdot \arccos \left(1-\frac{\lambda^{2}}{\tau_{0} \cdot J_{1}} \cdot \delta_{L i}\right)=\frac{1}{\lambda} \cdot\left[\varphi-\arcsin \frac{C_{3}}{\sqrt{C_{1}^{2}+C_{2}^{2}}}\right]
$$

Making the cosine of both members, results:

$$
\delta_{L i}\left(V_{f}^{t r}\right)=\frac{\tau_{0} \cdot J_{1}}{\lambda^{2}}\left\{1-\cos \cdot\left[\arcsin \frac{C_{1}}{\sqrt{C_{1}^{2}+C_{2}^{2}}}-\arcsin \frac{C_{3}}{\sqrt{C_{1}^{2}+C_{2}^{2}}}\right]\right\}
$$

where:

$$
\begin{aligned}
& \frac{1}{\lambda^{2}}=\frac{\delta_{1}}{\tau_{0} \cdot J_{1}} ; J_{1}=\frac{L_{p}}{A_{f}} \cdot\left[\frac{1}{E_{f}}+\frac{A_{f}}{A_{c} \cdot E_{c}}\right] ; J_{2}=\frac{E_{f} \cdot E_{c} \cdot A_{c}}{E_{c} \cdot A_{c}+E_{f} \cdot A_{f}} \\
& J_{3}=\frac{E_{f} \cdot A_{f} \cdot E_{c} \cdot A_{c}}{L_{p} \cdot\left(A_{c} \cdot E_{c}+A_{f} \cdot E_{f}\right)} ; C_{1}=\delta_{1}-\frac{\tau_{0} \cdot J_{1}}{\lambda^{2}} ; C_{2}=-\frac{\tau_{0} \cdot J_{1}}{\lambda^{2}} ; C_{3}=\frac{V_{f}^{t r}}{L_{p} \cdot J_{3} \cdot \lambda}+C_{1}
\end{aligned}
$$

Eq. (A8) gives a finite non null value only if $V_{f 1}^{b d} \geq V_{f}^{t r}$ (compare Fig. 2). The above constants can be further simplified as follows:

since $J_{3}=\frac{1}{J_{1}}, J_{3}$ will be eliminated and substituted, whenever it appears, by $\frac{1}{J_{1}}$;

since $\frac{1}{\lambda^{2}}=\frac{\delta_{1}}{\tau_{0} \cdot J_{1}}, C_{1}$ vanishes and $C_{2}$ can be written as $C_{2}=-\delta_{1}$ so that, in the various expressions, only $C_{3}$ will be kept.

On the basis of the above simplifications, and since $\cos ($ angle $)=\cos (-1 \cdot$ angle $)$, Eq. (A8) simplifies into: 


$$
\delta_{L i}\left(V_{f}^{t r}\right)=\delta_{1} \cdot\left\{1-\cos \cdot\left[\arcsin \frac{C_{3}}{\sqrt{C_{1}^{2}+C_{2}^{2}}}\right]\right\}
$$

As already stated in the paper, there must be a value $f_{c t m}^{*}$ of concrete mean tensile strength beyond which concrete no longer fractures and the equivalent value of the average available resisting bond length is equal to the average available resisting bond length $\bar{L}_{R f i}^{e q}=\bar{L}_{R f i} \cdot 1.0$. The value of $f_{c t m}^{*}$ can be determined by imposing the equality $V_{f i \text { max }}^{c f}=V_{f i \text { max }}^{b d}$ between the concrete fracture capacity $V_{f i}^{c f}$ and the corresponding maximum value of the bond transferred force $V_{f i}^{b d}$. This latter will be attained for a transfer length that is equal to $\bar{L}_{R f i}$, if it is $\bar{L}_{R f i} \leq L_{R f e}$ or that is equal to $L_{R f e}$ if it is $\bar{L}_{R f i}>L_{R f e}$. In general it can be written:

$$
V_{f i \text { max }}^{c f}\left(L_{R f i}\right)=V_{f i, \max }^{b d}\left(L_{R f i}\right)
$$

with:

$$
L_{R f i}=\left\{\begin{array}{lll}
\bar{L}_{R f i} & \text { if } & \bar{L}_{R f i} \leq L_{R f e} \\
L_{R f e} & \text { if } & \bar{L}_{R f i}>L_{R f e}
\end{array}\right.
$$

The expression $V_{f i, \max }^{c f}\left(L_{R f i}\right)$ can be simplified, with respect to Eq. (16) of Bianco et al. 2011, by considering a concrete prism, relevant to the average available resisting bond length, that has its bases orthogonal to $\bar{L}_{R f i}$, yielding:

$$
V_{f i \text { max }}^{c f}\left(L_{R f i}\right)=\min \left(L_{R f i} \cdot \tan \alpha ; \frac{b_{w}}{2}\right) \cdot \min \left(s_{f} \cdot \sin \beta ; 2 \cdot L_{R f i} \cdot \tan \alpha\right) \cdot f_{c t m}
$$

while the bond transferred force is given by Eq. (7.a) of Bianco et al. 2011, that is:

$$
V_{f i, \max }^{b d}\left(L_{R f i}\right)=L_{p} \cdot \frac{1}{J_{1}} \cdot \lambda \cdot\left\{C_{1} \cdot\left[\cos \left(\lambda \cdot L_{R f i}\right)-1\right]-C_{2} \cdot \sin \left(\lambda \cdot L_{R f i}\right)\right\}
$$

Substituting these latter into Eq. (A11), and taking into consideration the simplifications of Eq. (A9), one obtains:

$$
f_{c t m}^{*}=\frac{L_{p} \cdot \lambda \cdot \delta_{1} \cdot \sin \left(\lambda \cdot L_{R f i}\right)}{J_{1} \cdot \min \left(L_{R f i} \cdot \tan \alpha ; \frac{b_{w}}{2}\right) \cdot \min \left(s_{f} \cdot \sin \beta ; 2 \cdot L_{R f i} \cdot \tan \alpha\right)}
$$

With the simplifications of Eq. (A9), the value of imposed end slip in correspondence of which the bond-based constitutive law attains the peak, given by Eq. (13) of Bianco et al. 2011, simplifies into:

$$
\delta_{L 1}\left(\bar{L}_{R f i}^{e q}\right)= \begin{cases}\delta_{1} \cdot\left[1-\cos \left(\lambda \cdot \bar{L}_{R f i}^{e q}\right)\right] & \text { for } \bar{L}_{R f i}^{e q} \leq L_{R f e} \\ \delta_{1} & \text { for } \bar{L}_{R f i}^{e q}>L_{R f e}\end{cases}
$$


The expression of the maximum effective capacity $V_{f i, e f f}^{\max }=V_{f i, e f f}\left(\gamma_{\max }\right)$, given by Eq. (20) of Bianco et al. 2011, can be further simplified, introducing the simplifications of Eqs. (A9) into:

$$
V_{f i, e f f}^{\max }=V_{f i, e f f}\left(\gamma_{\max }\right)=\frac{\delta_{1} \cdot A_{2}}{2 \cdot L_{d} \cdot A_{3} \cdot \gamma_{\max }} \cdot\left[\frac{\pi}{2}-\arcsin \psi-\psi \cdot \sqrt{1-\psi^{2}}\right]
$$

in which

$$
\psi=1-A_{3} \cdot \gamma_{\max } \cdot L_{d}
$$

where $A_{3}$ and $L_{d}$ were already introduced in the main text. 